\title{
Characteristics of doripenem: a new broad-spectrum antibiotic
}

This article was published in the following Dove Press journal:

Drug Design, Development and Therapy

26 May 2009

Number of times this article has been viewed

\author{
Francisco Alvarez-Lerma' \\ Santiago Grau ${ }^{2}$ \\ Olivia Ferrández ${ }^{2}$ \\ 'Intensive Care Unit, ${ }^{2}$ Pharmacy \\ Department, Hospital Del Mar, \\ Barcelona, Spain
}

\begin{abstract}
Doripenem (S-4661) is a new parenteral antibiotic from the carbapenem class; similarly to imipenem and meropenem, it has a broad-spectrum activity against Gram-positive, Gram-negative, and anaerobic bacteria. It is active against multiresistant Gram-negative bacilli such as extended-spectrum beta-lactamase-producing (ESBL) Gram-negative Enterobacteriaceae and nonfermentative Gram-negative bacilli including some strains of Pseudomonas aeruginosa that are resistant to other carbapenems. Doripenem's chemical structure is similar to that of meropenem (substitution of one sulfamoxil-aminomethyl chain for the dimethyl-carboxyl chain), and has one 1-beta-methyl chain which provides resistance to dehydropeptidase-I enzyme. The clinical trials conducted so far have focused on the treatment of severe infections such as complicated intra-abdominal infections, complicated urinary tract infections and pyelonephritis, nosocomial pneumonia, and ventilator-associated pneumonia. Given its activity profile and the results from the clinical trials, this antibiotic may be used for empirical treatment of multibacterial infections produced by potentially multiresistant Gram-negative bacilli. In 2007, the US Food and Drug Administration approved the use of doripenem for the treatment of complicated intra-abdominal infections and complicated urinary tract infections. The European Medicines Agency has approved the use of doripenem for the same indications in addition to nosocomial pneumonia regardless of whether it is ventilator-associated or not.
\end{abstract}

Keywords: doripenem, antimicrobial activity, clinical efficacy, pharmacokinetics, tolerability

\section{Pharmacodynamic profile Mechanism of action}

Like the other beta-lactams, doripenem inhibits bacterial cell wall biosynthesis by inactivating the penicillin-binding proteins (PBP), which results in bacterial cell death. ${ }^{1}$ Doripenem has shown a marked affinity for PBP2 and 4 in strains of Escherichia coli MC4100, for PBP2 and PBP3 in strains of Pseudomonas aeruginosa PAO1 and 27853, and for PBP 1 in Staphylococcus aureus., ${ }^{2,3}$ Because these PBP are considered a fundamental target, the profile described above justifies the broad spectrum of the carbapenem against Gram-negative microorganisms. Furthermore, its greater activity against $P$. aeruginosa compared to imipenem is due to its higher affinity for PBP2 and PBP3 in strains of this specie. Doripenem is resistant to most beta-lactamases produced by Gram-negative and Gram-positive microorganisms, including penicillinases and cephalosporinases. However, it is hydrolyzed by metallo-beta-lactamases (MBL) and carbapenemases. Results from an in vitro study show a greater stability of doripenem
Alvarez-Lerma

Intensive Care Unit, Hospital del Mar,

Passeig Marítim, 25-29, 08003,

Barcelona, Spain

Tel +34932483125

Fax +34932483254

Email falvarez@imas.imim.es 
compared to imipenem after exposure to a human recombinant dehydropeptidase I. ${ }^{4}$ Although this greater stability was first attributed to the 1-beta-methyl group in its structure, this association was later ruled out, based on its lesser stability compared to other carbapenems that have this chemical group. Thus, other functional groups, the distance between them, as well as other factors, may play a role in the stability of these antibiotics in regards to dehydropeptidase I.

\section{Antibacterial activity}

In vitro studies have shown that doripenem has a spectrum of activity similar to that of imipenem against Gram-positive microorganisms, while it is similar to meropenem against Gram-negative microorganisms. ${ }^{5-7}$

Table 1 shows the doripenem-sensitive microorganisms most often involved in infections for which the carbapenem is indicated. ${ }^{1}$ Similarly to the others in the group, the activity of this carbapenem is limited against strains of methicillinresistant Staphylococcus aureus (MRSA), Enterococcus faecium, and Stenotrophomonas maltophilia. US Food and Drug Administration (FDA) and European Medicines Agency (EMEA) definitions of doripenem's breakpoints are shown in Table 2., ${ }^{8,9}$

Table I Indications for which doripenem is approved as monotherapy and the microorganisms involved

\begin{tabular}{|c|c|}
\hline Indication & Microorganism \\
\hline $\begin{array}{l}\text { Complicated intra-abdominal } \\
\text { infection }\end{array}$ & $\begin{array}{l}\text { Escherichia coli } \\
\text { Klebsiella pneumoniae } \\
\text { Pseudomonas aeruginosa } \\
\text { Bacteroides caccae } \\
\text { Bacteroides fragilis } \\
\text { Bacteroides thetaiotaomicron } \\
\text { Bacteroides uniformis } \\
\text { Bacteroides vulgatus } \\
\text { Streptococcus intermedius } \\
\text { Streptococcus constellatus } \\
\text { Peptostreptococcus micros }\end{array}$ \\
\hline $\begin{array}{l}\text { Complicated urinary tract } \\
\text { infection, including pyelonephritis }\end{array}$ & $\begin{array}{l}\text { Escherichia coli } \\
\text { Klebsiella pneumoniae } \\
\text { Proteus mirabilis } \\
\text { Pseudomonas aeruginosa } \\
\text { Acinetobacter baumannii }\end{array}$ \\
\hline $\begin{array}{l}\text { Nosocomial pneumonia, including } \\
\text { ventilator-associated pneumonia }\end{array}$ & $\begin{array}{l}\text { Escherichia coli } \\
\text { Klebsiella pneumoniae } \\
\text { Pseudomonas aeruginosa } \\
\text { Staphylococcus aureus } \\
\text { Streptococcus pneumoniae } \\
\text { Enterobacter cloacae } \\
\text { Acinetobacter baumannii } \\
\text { Haemophilus influenzae }\end{array}$ \\
\hline
\end{tabular}

\section{Aerobic Gram-negative microorganisms}

Different studies have shown a high in vitro activity of doripenem against aerobic Gram-negative microorganisms (Table 3). ${ }^{6,7,10-16}$

One of the most extensive studies was conducted in 2003 as part of a global microbiological surveillance program, and included strains from more than 70 medical centers in North America, South America, and Europe. ${ }^{10}$ Strains of both Haemophilus influenzae and Moraxella catarrhalis were susceptible to doripenem (minimum inhibitory concentration required to inhibit the growth of $90 \%$ of organisms $\left[\mathrm{MIC}_{90}\right]$ $0.25 \mathrm{mg} / \mathrm{L}$ and $\mathrm{MIC}_{50} 0.06 \mathrm{mg} / \mathrm{L}$ for $H$. influenzae; $\mathrm{MIC}_{90}$ $0.03 \mathrm{mg} / \mathrm{L}$ and $\mathrm{MIC}_{50} 0.016 \mathrm{mg} / \mathrm{L}$ for $M$. catarrhalis), but the activity was lower than that observed for meropenem. ${ }^{10}$ On the other hand, ertapenem's activity was higher than doripenem's against beta-lactamase-producing strains of $H$. influenzae. ${ }^{6}$ Doripenem's $\mathrm{MIC}_{50}$ and $\mathrm{MIC}_{90}$ against Enterobacteriaceae were $0.03-0.12 \mathrm{mg} / \mathrm{L}$ and $0.03-0.5 \mathrm{mg} / \mathrm{L}$, respectively; these were similar to those observed for meropenem $\left(\mathrm{MIC}_{50} 0.016-0.06\right.$ and $\left.\mathrm{MIC}_{90} 0.03-0.12 \mathrm{mg} / \mathrm{L}\right)$, and lower than those described for imipenem $\left(\mathrm{MIC}_{50} \leq 0.5-2\right.$ and $\left.\mathrm{MIC}_{90} 0.5-4 \mathrm{mg} / \mathrm{L}\right)$. Similarly, doripenem's $\mathrm{MIC}_{50}$ and $\mathrm{MIC}_{90}$ were $\leq 0.06-0.25 \mathrm{mg} / \mathrm{L}$ and $\leq 0.06-0.5 \mathrm{mg} / \mathrm{L}$, respectively, in 36,614 Enterobacteriaceae isolates from more than 60 medical centers in North America, Latin America, Europe, and the Asian-Pacific area. ${ }^{15}$ These results coincide with those from other studies in which doripenem's $\mathrm{MIC}_{90}$ in Enterobacteriaceae strains was between 0.03 and $0.5 \mathrm{mg} / \mathrm{L}$, with the exception of strains of Proteus mirabilis, in which $\mathrm{MIC}_{90}$ was $1 \mathrm{mg} / \mathrm{L} .^{5,7,12}$ Doripenem's activity against strains

Table 2 Breakpoints defined by FDA and EMEA

\begin{tabular}{llllr}
\hline & \multicolumn{2}{l}{ EMEA } & \multicolumn{2}{l}{ FDA } \\
\cline { 2 - 5 } Minimum inhibitory concentration \\
\cline { 2 - 5 } Microorganism & S & R & S & R \\
\hline Staphylococcus spp.* & $\leq \mathrm{I}$ & $>4$ & - & - \\
Enterobacteriaceae & $\leq \mathrm{I}$ & $>4$ & $\leq 0.5$ & - \\
Acinetobacter spp. & $\leq \mathrm{I}$ & $>4$ & - & - \\
Acinetobacter baumannii & - & - & $\leq \mathrm{I}$ & - \\
Pseudomonas aeruginosa & - & - & $\leq 2$ & - \\
Pseudomonas spp. & $\leq \mathrm{I}$ & $>4$ & - & - \\
Streptococcus pneumoniae & $\leq \mathrm{I}$ & $>4$ & - & - \\
Haemophilus spp. & $\leq \mathrm{I}$ & $>4$ & - & - \\
Anaerobes & $\leq \mathrm{I}$ & $>4$ & $\leq \mathrm{I}$ & \\
\hline
\end{tabular}

Note: *From methicillin breakpoint.

Abbreviations: EMEA, European Medicines Agency; FDA, US Food and Drug Administration; $R$, resistant; $S$, sensitive. 
Table 3 In vitro activity of doripenem against various species of Gram-negative microorganisms

\begin{tabular}{|c|c|c|c|c|}
\hline Microorganism & Strains tested $(n)$ & $\mathrm{MIC}_{50}$ & $\mathrm{MIC}_{90}$ & Range \\
\hline Acinetobacter spp. & 155 & 0.5 & 4 & $0.016->16$ \\
\hline Acinetobacter spp. & 3844 & 2 & $>8$ & \\
\hline Acinetobacter baumannii & 33 & 0.5 & 16 & $0.03->32$ \\
\hline Acinetobacter baumannii & 2982 & 2 & $>8$ & \\
\hline Aeromonas spp. & 44 & 0.5 & 1 & $0.03-4$ \\
\hline Aeromonas spp. & 172 & 0.5 & 2 & \\
\hline Bordetella pertussis & 52 & 0.25 & 0.5 & $0.25-0.5$ \\
\hline Burkholderia cepacia & 20 & 2 & 8 & $0.12->16$ \\
\hline Burkholderia cepacia & 25 & 8 & 8 & $4-16$ \\
\hline Burkholderia cepacia ${ }^{a}$ & 200 & 8 & 32 & $0.5-256$ \\
\hline Citrobacter spp. & 136 & 0.03 & 0.06 & $\leq 0.008-2$ \\
\hline Citrobacter freundii & 22 & 0.032 & 0.063 & $0.032-0.125$ \\
\hline Enterobacter spp. & 601 & 0.06 & 0.12 & $\leq 0.008-4$ \\
\hline Enterobacter spp. AmpC & 33 & - & 0.12 & - \\
\hline Enterobacter cloacae & 30 & 0.032 & 0.063 & $0.032-0.125$ \\
\hline Non-ESBL-producing Escherichia coli & 15478 & $\leq 0.06$ & $\leq 0.06$ & - \\
\hline Non-ESBL-producing Escherichia coli & 3023 & 0.03 & 0.03 & $\leq 0.008-1$ \\
\hline ESBL Escherichia coli & 2363 & $\leq 0.06$ & $\leq 0.06$ & - \\
\hline ESBL Escherichia coli & $12 \mid$ & 0.03 & 0.06 & $0.016-1$ \\
\hline Beta-lactamase-negative Haemophilus influenzae & 1426 & 0.06 & 0.25 & $\leq 0.008-2$ \\
\hline Beta-lactamase-positive Haemophilus influenzae & 398 & 0.12 & 0.25 & $\leq 0.008-1$ \\
\hline Beta-lactamase-negative Haemophilus influenzae & 33 & 0.12 & 1 & $\leq 0.015-1$ \\
\hline Beta-lactamase-positive Haemophilus influenzae & 28 & 0.12 & 0.5 & $0.12-1$ \\
\hline Non-ESBL-producing Klebsiella spp. & 1107 & 0.03 & 0.06 & $0.016->16$ \\
\hline ESBL Klebsiella spp. & 155 & 0.06 & 0.12 & $0.016-8$ \\
\hline Non-ESBL-producing Klebsiella pneumoniae & 5387 & $\leq 0.06$ & $\leq 0.06$ & - \\
\hline Non-ESBL-producing Klebsiella pneumoniae & 26 & - & 0.03 & - \\
\hline ESBL Klebsiella pneumoniae & 2444 & $\leq 0.06$ & 1 & - \\
\hline ESBL Klebsiella pneumoniae & 34 & - & 0.06 & - \\
\hline Klebsiella oxytoca & 38 & 0.063 & 0.063 & $0.032-0.063$ \\
\hline Non-ESBL-producing Klebsiella oxytoca & 1013 & $\leq 0.06$ & $\leq 0.06$ & - \\
\hline ESBL-producing Klebsiella oxytoca & 277 & $\leq 0.06$ & 0.12 & - \\
\hline Moraxella catarrhalis & 108 & 0.016 & 0.03 & $\leq 0.008-0.5$ \\
\hline Morganella morganii & 32 & 0.125 & 0.25 & $0.063-0.5$ \\
\hline Proteus mirabilis & 307 & 0.12 & 0.25 & $0.016-0.5$ \\
\hline ESBL-producing Proteus mirabilis & II & 0.12 & 0.25 & $0.06-0.25$ \\
\hline Proteus vulgaris & 30 & 0.25 & 0.5 & $0.063-0.5$ \\
\hline Indol-positive Proteae & 148 & 0.12 & 0.5 & $0.03-1$ \\
\hline Non-ESBL-producing Proteus mirabilis & 1766 & 0.12 & 0.25 & - \\
\hline ESBL-producing Proteus mirabilis & 129 & 0.25 & 0.5 & - \\
\hline Providencia rettgeri & 21 & 0.125 & 0.25 & $0.063-1$ \\
\hline Pseudomonas aeruginosa & 829 & 0.5 & 8 & $0.03->16$ \\
\hline Pseudomonas aeruginosa & 9256 & 0.5 & 8 & - \\
\hline Pseudomonas aeruginosa $\mathrm{R}$ carbapenems & 49 & - & $>32$ & - \\
\hline Pseudomonas aeruginosa $\mathrm{R}$ carbapenems & 34 & 8 & $>32$ & $0.5->32$ \\
\hline
\end{tabular}


Table 3 (Continued)

\begin{tabular}{|c|c|c|c|c|}
\hline Microorganism & Strains tested $(n)$ & $\mathrm{MIC}_{50}$ & $\mathrm{MIC}_{90}$ & Range \\
\hline MBL-producing Pseudomonas aeruginosa & 15 & $>32$ & $>32$ & $4->32$ \\
\hline Pseudomonas aeruginosa S imipenem & 83 & 0.25 & 2 & $0.063-8$ \\
\hline Pseudomonas aeruginosa $\mathrm{R}$ imipenem & 32 & 8 & 8 & $2-16$ \\
\hline Pseudomonas aeruginosa $\mathrm{R}$ ceftazidime & 39 & 2 & 8 & $0.063-16$ \\
\hline Pseudomonas aeruginosa R ciprofloxacin & 16 & 0.5 & 8 & $0.125-8$ \\
\hline Pseudomonas aeruginosa $\mathrm{R}$ gentamicin & 37 & 0.5 & 8 & $0.063-16$ \\
\hline Pseudomonas aeruginos $a^{\mathrm{a}}$ & 82 & 0.25 & 2 & $0.25-256$ \\
\hline Mucoid Pseudomonas aeruginosa ${ }^{a}$ & 200 & 8 & 32 & $0.25-512$ \\
\hline Non-mucoid Pseudomonas aeruginosa ${ }^{a}$ & 200 & 8 & 64 & $0.25-512$ \\
\hline Other Pseudomonas spp. & 438 & 0.5 & 4 & - \\
\hline Salmonella spp. & 530 & 0.06 & 0.06 & $0.016-0.25$ \\
\hline Serratia spp. & 187 & 0.12 & 0.25 & $0.03-1$ \\
\hline Serratia marcescens & 30 & 0.125 & 0.25 & $0.063-4$ \\
\hline Shigella spp. & 161 & 0.03 & 0.06 & $0.016-0.06$ \\
\hline Stenotrophomonas maltophilia & 1269 & $>8$ & $>8$ & - \\
\hline Stenotrophomonas maltophilia & 80 & $>16$ & $>16$ & $1->16$ \\
\hline
\end{tabular}

Notes: aStrains isolated from patients with cystic fibrosis. Data from Fritsche et al, ${ }^{10}$ Tsuji et al, ${ }^{11}$ Jones et al, ${ }^{67,12}$ Traczewski et al, ${ }^{13} \mathrm{Chen}$ et al, ${ }^{14} \mathrm{Mendes}$ et al, ${ }^{15} \mathrm{Castanheira}$ et al. ${ }^{16}$ Abbreviations: AmpC, ampicillinases; ESBL, extended-spectrum beta-lactamases; MBL, metallo-beta-lactamases; MIC, minimum inhibitory concentrations; R, resistant; S, sensitive.

of extended-spectrum beta-lactamase (ESBL) producing Enterobacteriaceae such as E. coli and Klebsiella spp. is similar to that observed for meropenem, and four to eight times higher than ertapenem's and imipenem's. ${ }^{7}$ Against strains of Enterobacter spp. doripenem and meropenem showed an activity eight times higher than that observed for imipenem and ertapenem $\left(\mathrm{MIC}_{90} 0.12 \mathrm{mg} / \mathrm{L}\right.$ vs $\mathrm{MIC}_{90}$ $1 \mathrm{mg} / \mathrm{L}$, respectively). ${ }^{10}$ Similarly, the MIC of doripenem against strains of AMPc-producing Enterobacter spp. ranged between $0.06 \mathrm{mg} / \mathrm{L}$ and $0.5 \mathrm{mg} / \mathrm{L}$, comparable to the activity of meropenem (MIC $\leq 0.03-0.25 \mathrm{mg} / \mathrm{L}$ ), and higher than that of imipenem (MIC $0.12-2 \mathrm{mg} / \mathrm{L}$ ) and ertapenem (MIC $0.06-1 \mathrm{mg} / \mathrm{L}$ ). ${ }^{17}$ Other doripenem's MIC values against imipenem-resistant Enterobacter spp. isolated from bacteremia have been reported (doripenem MIC 0.03-2 mg/L, meropenem MIC 0.06-8 mg/L, ertapenem MIC $0.015-64 \mathrm{mg} / \mathrm{mL}){ }^{18}$

In contrast, against strains of $P$. mirabilis, Serratia spp. and Salmonella spp. doripenem's $\mathrm{MIC}_{90}$ was higher than that observed for meropenem and ertapenem, and lower than that observed for imipenem. ${ }^{10}$ Several studies have concluded that the activity of doripenem is comparable to that of meropenem against strains of $P$. aeruginosa and Acinetobacter spp. ${ }^{10,11,19}$ Thus, doripenem and meropenem were the most active carbapenems against strains of these bacteria, displaying a higher activity than imipenem and ertapenem. ${ }^{6}, 10$ Additionally, doripenem's activity was similar to that of meropenem against imipenem-sensitive strains of $P$. aeruginosa, with a $\mathrm{MIC}_{90}$ of $2 \mathrm{mg} / \mathrm{mL}$, and a $\mathrm{MIC}_{50}$ of $0.25 \mathrm{mg} / \mathrm{L} ;{ }^{19}$ its activity was higher than that of all other carbapenems against strains of $P$. aeruginosa that were resistant to imipenem. ${ }^{7}$ Doripenem's MIC was $\leq 4 \mathrm{mg} / \mathrm{L}$ for most imipenem-resistant P. aeruginosa isolates from bacteremia included in other study ${ }^{20}$ Similarly, doripenem showed a high activity against strains of $P$. aeruginosa that were resistant to ceftazidime, ciprofloxacin, imipenem or gentamicin; the activity was comparable to that of meropenem, and higher than that of the other antibiotics tested. ${ }^{11,21}$ As expected, doripenem, like the other carbapenems, had no activity against strains of carbapenemase-producing Gram-negative bacilli. ${ }^{17}$

Doripenem's activity is superior to that of imipenem and meropenem in A. baumannii clinical isolates producing the OXA-58 carbapenemase (doripenem's $\mathrm{MIC}_{50}$ and $\mathrm{MIC}_{90}$ of 4 and $8 \mathrm{mg} / \mathrm{L}$, respectively, and imipenem's and meropenem's $\mathrm{MIC}_{50}$ and $\mathrm{MIC}_{90}$ of 16 and $64 \mathrm{mg} / \mathrm{L}$, respectively). ${ }^{22}$

\section{Aerobic Gram-positive microorganisms}

According to various studies conducted, doripenem's activity against Gram-positive microorganisms is comparable to 
imipenem's and superior to meropenem's and ertapenem's (Table 4). ${ }^{6,10,11,23}$

Doripenem proved to be more powerful than other carbapenems against strains of oxacillin-sensitive $S$. aureus (OSSA), with a $\mathrm{MIC}_{90}$ and a $\mathrm{MIC}_{50}$ of $0.06 \mathrm{mg} / \mathrm{L}$, and against oxacillin-sensitive coagulase-negative Staphylococcus spp. with at $\mathrm{MIC}_{90}$ of $0.06 \mathrm{mg} / \mathrm{L}$ and a $\mathrm{MIC}_{50}$ of $0.03 \mathrm{mg} / \mathrm{L},{ }^{6,10}$ while for oxacillin-resistant strains, the $\mathrm{MIC}_{90}$ ranged between $4 \mathrm{mg} / \mathrm{L}$ for strains of $S$. epidermidis, and $32 \mathrm{mg} / \mathrm{L}$ for strains coagulase-negative Staphylococcus spp. These values were comparable to those observed with imipenem, and lower than those observed with meropenem and ertapenem. ${ }^{5,19}$ Doripenem's activity against strains of Enterococcus faecalis and Enterococcus spp. other than E. faecium was lower than imipenem's, and higher than that observed with meropenem or ertapenem. ${ }^{10}$ Thus the $\mathrm{MIC}_{90}$ for doripenem was $8 \mathrm{mg} / \mathrm{L}$, vs $4 \mathrm{mg} / \mathrm{L}$ for imipenem, $16 \mathrm{mg} / \mathrm{L}$ for meropenem, and $>8 \mathrm{mg} / \mathrm{L}$ for ertapenem, while the $\mathrm{MIC}_{50}$ for doripenem was $4 \mathrm{mg} / \mathrm{L}$, vs $1 \mathrm{mg} / \mathrm{L}$ for imipenem and $8 \mathrm{mg} / \mathrm{L}$ for meropenem and ertapenem. Similar results were obtained in another study with strains of E. faecalis, but a lower $\mathrm{MIC}_{90}$ was observed for imipenem, $2 \mathrm{mg} / \mathrm{L} .{ }^{5}$
Like the rest of the carbapenems, doripenem showed little activity against strains of E. faecium, with values of $\mathrm{MIC}_{90}$ and $\mathrm{MIC}_{50}$ over $16 \mathrm{mg} / \mathrm{L} .{ }^{5,6,10}$ These values were independent from the pattern of vancomycin-resistance showed in the strains examined. Doripenem's activity was comparable to that of imipenem against strains of Streptococcus in the viridans group, with $\mathrm{MIC}_{90}$ of $0.5 \mathrm{mg} / \mathrm{L}$ and $\mathrm{MIC}_{50}$ of $0.03 \mathrm{mg} / \mathrm{L} .{ }^{10}$ Based on the $\mathrm{MIC}_{50}$, the activity observed was twice as high as that of meropenem $\left(\mathrm{MIC}_{50}\right.$ $0.06 \mathrm{mg} / \mathrm{L}, \mathrm{MIC}_{90} 0.5 \mathrm{mg} / \mathrm{L}$ ), and four times as high as that of ertapenem $\left(\mathrm{MIC}_{50} 0.12 \mathrm{mg} / \mathrm{L}, \mathrm{MIC}_{90} 1 \mathrm{mg} / \mathrm{L}\right)$. Additionally, doripenem showed an excellent activity against strains of beta-hemolytic Streptococcus spp., Streptococcus pyogenes, and Streptococcus agalactiae, with $\mathrm{MIC}_{90}$ of $0.03 \mathrm{mg} / \mathrm{L}$ and $\mathrm{MIC}_{50} \leq 0.008 \mathrm{mg} / \mathrm{L} .{ }^{5,10}$ The activity of the various carbapenems was comparable against strains of Streptococcus pneumoniae, but differences were observed depending on the penicillin-resistance pattern. ${ }^{5}$ Thus, the $\mathrm{MIC}_{50}$ against penicillin-sensitive strains was $\leq 0.008 \mathrm{mg} / \mathrm{L}$ for doripenem, meropenem, and imipenem, and $0.015 \mathrm{mg} / \mathrm{L}$ for ertapenem, while in penicillin-resistant strains, it was $0.5 \mathrm{mg} / \mathrm{L}$, except for ertapenem, whose MIC was $1 \mathrm{mg} / \mathrm{L}$.

Table 4 In vitro activity of doripenem against various species of Gram-positive microorganisms

\begin{tabular}{|c|c|c|c|c|}
\hline Microorganism & Strains tested $(n)$ & $\mathrm{MIC}_{50}$ & $\mathrm{MIC}_{90}$ & Range \\
\hline Enterococcus faecalis (1206) and other non-faecium species (70) & 1276 & 4 & 8 & $\leq 0.008->16$ \\
\hline Enterococcus faecalis ${ }^{\mathrm{a}}$ & 45 & 4 & 16 & $\leq 0.015->32$ \\
\hline Enterococcus faecium & 198 & $>16$ & $>16$ & $0.03->16$ \\
\hline Staphylococcus aureus S oxacillin & 2705 & 0.06 & 0.06 & $\leq 0.008-4$ \\
\hline Coagulase-negative Staphylococcus S oxacillin & 297 & 0.03 & 0.06 & $\leq 0.008-8$ \\
\hline Staphylococcus aureus S methicillin & 75 & 0.03 & 0.06 & $0.03-0.06$ \\
\hline Staphylococcus aureus $\mathrm{R}$ methicillin & 75 & 0.5 & 8 & $0.06-32$ \\
\hline Staphylococcus aureus I vancomycin & 4 & 16 & 16 & $0.06-16$ \\
\hline Streptococcus pneumoniae & 885 & 0.016 & 0.5 & $\leq 0.008-1$ \\
\hline Streptococcus pneumoniae $S$ penicillin & 20 & $\leq 0.015$ & $\leq 0.015$ & $\leq 0.015$ \\
\hline Streptococcus pneumoniae I penicillin & 10 & 0.03 & 0.25 & $\leq 0.015-0.5$ \\
\hline Streptococcus pneumoniae $\mathrm{R}$ penicillin & 23 & 0.5 & 1 & $0.25-2$ \\
\hline Streptococcus pneumoniae $S$ penicillin & 25 & 0.008 & 0.008 & $0.004-0.016$ \\
\hline Streptococcus pneumoniae $\mathrm{R}$ penicillin & 25 & 0.25 & 0.5 & $0.016-2$ \\
\hline Streptococcus viridans group & 140 & 0.03 & 0.5 & $\leq 0.008->16$ \\
\hline Streptococcus viridans group S penicillin & 23 & 0.03 & 0.06 & $\leq 0.015-0.12$ \\
\hline Streptococcus viridans group I penicillin & 13 & 0.25 & 0.5 & $\leq 0.015-2$ \\
\hline Streptococcus viridans group $R$ penicillin & 13 & 2 & 4 & $0.25-4$ \\
\hline Beta-hemolytic Streptococcus & 397 & $\leq 0.008$ & 0.03 & $\leq 0.008-0.25$ \\
\hline Streptococcus pyogenes & 42 & $\leq 0.004$ & $\leq 0.004$ & $\leq 0.004$ \\
\hline Streptococcus agalactiae & 32 & 0.016 & 0.032 & $0.016-0.032$ \\
\hline
\end{tabular}

Notes: aincludes four van A strains and two van B strains. Data from Fritsche et al, ${ }^{10}$ Tsuji et al, ${ }^{11}$ Jones et al, ${ }^{6,7}$ Brown et al. ${ }^{23}$

Abbreviations: I, intermediate sensitivity; MIC, minimum inhibitory concentrations; R, resistant; S: sensitive. 


\section{Anaerobic microorganisms}

Doripenem has shown a high in vitro activity against a large number of anaerobic microorganisms (Table 5), with a MIC ranging, in various studies, from $\leq 0.015$ to $32 \mathrm{mg} / \mathrm{L} .^{6,24-28}$

The highest MIC values were obtained against strains of Clostridium difficile, but they were lower than the MICs obtained with ertapanem and meropenem. ${ }^{24,27}$ Doripenem has shown a high activity against strains of Bacteroides fragilis, with $\mathrm{MIC}_{50}$ and $\mathrm{MIC}_{90}$ values of $0.25 \mathrm{mg} / \mathrm{L}$ and $0.5 \mathrm{mg} / \mathrm{L}$, respectively. ${ }^{6}$

\section{Mechanisms of resistance}

Various resistance mechanisms to carbapenems have been identified; they include the loss of porin OprD, the expression of efflux systems, the production of carbapenemases, and the alteration of certain penicillin-binding proteins (PBPs). ${ }^{29}$

Table 5 In vitro activity of doripenem against various species of anaerobic microorganisms

\begin{tabular}{|c|c|c|c|c|}
\hline Microorganism & Strains tested $(n)$ & $\mathrm{MIC}_{50}$ & $\mathrm{MIC}_{90}$ & Range \\
\hline Anaerococcus spp. ${ }^{a}$ & 22 & $\leq 0.015$ & 0.06 & $\leq 0.015-0.5$ \\
\hline Bacteroides caccae & 16 & 0.5 & 2 & $0.25-4$ \\
\hline Bacteroides distasonis & 15 & 0.5 & 2 & $0.125-2$ \\
\hline Bacteroides fragilis & 26 & 0.25 & 0.5 & $0.12-1$ \\
\hline Bacteroides fragilis & 81 & 0.5 & 1 & $0.25-16$ \\
\hline Bacteroides fragilis & 198 & 0.5 & 1 & $0.125-16$ \\
\hline Bacteroides ovatus & 20 & 0.5 & 1 & $0.12-2$ \\
\hline Bacteroides ovatus & 35 & 0.5 & 2 & $0.25-4$ \\
\hline Bacteroides thetaiotaomicron & 42 & 0.5 & 1 & $0.12-2$ \\
\hline Bacteroides thetaiotaomicron & 78 & 0.5 & 1 & $0.125-8$ \\
\hline Bacteroides uniformis & 21 & 0.5 & 1 & $0.125-1$ \\
\hline Bacteroides vulgatus & 31 & 0.5 & 2 & $0.125-2$ \\
\hline Bilophila wadsworthia & 21 & 0.12 & 0.12 & $0.03-0.12$ \\
\hline Clostridium difficile & 110 & 1 & 2 & $0.5-4$ \\
\hline Clostridium perfringens $^{\mathrm{a}}$ & 10 & $\leq 0.015$ & 0.03 & $\leq 0.015-0.03$ \\
\hline Clostridium perfringens & 13 & 0.06 & 0.125 & $0.06-0.125$ \\
\hline Corynebacterium amycolatum ${ }^{\mathrm{a}}$ & 14 & 0.5 & 2 & $0.06->32$ \\
\hline $\begin{array}{l}\text { Corynebacterium spp. group I (C. aurimucosum, } \\
\text { C. jeikeium, C. minutissimum, C. urealyticum) }\end{array}$ & 14 & 1 & 8 & $0.25->32$ \\
\hline $\begin{array}{l}\text { Corynebacterium spp. group I (C. striatum, } \\
\text { C. accolens, C. simulans, C. xerosis) }{ }^{\mathrm{a}}\end{array}$ & 18 & 0.125 & 0.25 & $\leq 0.015-0.25$ \\
\hline Finegoldia magna ${ }^{a}$ & 30 & 0.06 & 0.125 & $\leq 0.015-0.25$ \\
\hline Fusobacterium spp. & 15 & 0.031 & 1 & $0.03-1$ \\
\hline Peptoniphilus asaccharolyticus ${ }^{\mathrm{a}}$ & 20 & $\leq 0.015$ & 0.06 & $\leq 0.015-0.125$ \\
\hline Peptostreptococcus spp. ${ }^{\mathrm{a}}$ & 17 & 0.06 & 0.25 & $0.03-0.25$ \\
\hline Peptostreptococcus magnus & 21 & 0.0625 & 0.125 & $0.0156-0.5$ \\
\hline Porphyromonas spp. & 20 & 0.031 & 0.5 & $0.03-4$ \\
\hline Prevotella spp. & 20 & 0.12 & 0.25 & $0.03-1$ \\
\hline Prevotella bivia & 28 & 0.25 & 1 & $0.125-4$ \\
\hline Prevotella intermedia/nigrescens & 10 & 0.031 & 0.062 & $0.03-0.06$ \\
\hline Prevotella oris/buccae & 10 & 0.12 & 0.5 & $0.03-0.5$ \\
\hline Propionibacterium acnes ${ }^{\mathrm{a}}$ & 14 & 0.06 & 0.125 & $0.03-0.25$ \\
\hline Propionibacterium acnes & 18 & 0.06 & 0.06 & $0.06-0.06$ \\
\hline Propionibacterium spp. & 13 & 0.06 & 0.06 & $0.06-0.06$ \\
\hline Sutterella wadsworthensis & 12 & 4 & 8 & $0.06-32$ \\
\hline
\end{tabular}

Notes: aStrains isolated from patients with infected diabetic foot wound. Data from Goldstein et al, ${ }^{26}$ Jones et al, ${ }^{6,7}$ Wexler et al, ${ }^{24} \mathrm{Hecht}$ et al, ${ }^{27}$ Mikamo et al, ${ }^{28}$ Snydman et al. ${ }^{25}$ 
In the specific case of doripenem, treatment with the carbapenem has been associated with a reduced potential of selection of resistance in strains of $P$. aeruginos $a$, for which reason it may be a good alternative to cover infections by these microorganisms. ${ }^{7,30} \mathrm{With}$ regard to the loss of porins, an experiment with five mutant strains selected after exposure to doripenem identified the loss of OprD in some of the strains, which produced cross-resistance only with the other carbapenems. ${ }^{30}$

Another study had the objective of determining the specific substrates of three different efflux systems, MexABOprM, MexCD-OprJ, and MexXY-OprM, in strains of P. aeruginosa ${ }^{31}$ For this purpose, three isogenic mutants were constructed, each constitutively producing mostly one of the three efflux systems and neither of the other two; the isogenic mutants lacking this mechanism were then compared. All efflux pumps expelled different antibiotics, including quinolones, macrolides, tetracyclines, lincomycin, chloramphenicol, most penicillins and cephalosporins, meropenem, and doripenem. However, polymyxin B and imipenem were not affected. Another study included two strains of B. fragilis, WAL 108 and WAL $219 ; ;^{32}$ its objective was to determine the potential of various antimicrobials, including doripenem, to select mutant strains of multi-resistant $B$. fragilis by overexpression of bmeB efflux pumps. Ampicillin, doripenem, imipenem, levofloxacin, and metronidazole selected multiresistant mutants derived form both strains. All mutant strains derived from WAL 219, except those selected with doripenem, showed more than twice an overexpression of one or more of the bmeB genes compared to strains selected from WAL 108. Although the strains derived from WAL 219 after exposure to doripenem did not overexpress any bmeB efflux pump, they did show multidrug resistance, which means that there is overexpression of other genes that codify other efflux pumps.

Like the rest of the carbapenems, doripenem's activity is decreased in the presence of carbapenemases produced by strains of certain microorganisms. ${ }^{17}$ Thus, the MIC increased from $0.25-1 \mu \mathrm{g} / \mathrm{mL}$ to $16-64 \mu \mathrm{g} / \mathrm{mL}$ in strains of metallo-betalactamase (MBL)- or OXA-type carbapenemase-producing Acinetobacter spp. and from $8 \mu \mathrm{g} / \mathrm{mL}$ to more than $64 \mu \mathrm{g} / \mathrm{mL}$ in strains of IMP-, KPC-, and SME-type beta-lactamaseproducing Klebsiella spp. and Serratia spp. However, based on the sensitivity displayed by IMP-1 and NMC-A beta-lactamaseproducing strains of $E$. coli by transconjugation, resistance to carbapenems might require other additional mechanisms.

Although the enzymes described above have been more often implicated in the inactivation of carbapenems, these antibiotics did not behave like inactivators of the enzyme
CTX-M-14 produced by strains of E. coli TUM1 $121 .^{33}$ However, the enzyme's catalytic activity was very reduced, according to the values obtained for kinetic parameters at steady state.

Although doripenem has shown a high affinity for all types of PBP in strains of penicillin-sensitive $S$. pneumoniae, it has been reduced in resistant strains, especially when PBP2 $x$ and PBP2b are affected. ${ }^{34}$

Associating doripenem with an aminoglycoside seems to reduce the potential selection of strains that are highly resistant to carbapenem, according to the results observed after exposing six strains of $P$. aeruginos $a$ from patients with bacteremia to doripenem or to the association of carbapenem and gentamicin. ${ }^{35}$

The various resistance mechanisms described above come mostly from in vitro studies with doripenem. For this reason, more studies are required in order to learn more about these mechanisms more precisely, and to understand their effects on routine clinical practice.

\section{Bactericidal activity}

Doripenem has shown an excellent bactericidal activity against aerobic and anaerobic microorganisms, comparable to that of the other carbapenems, and better than that of ceftazidime. After 48 hours of exposure to doripenem at a concentration of twice the MIC (2XMIC), a 99.9\% eradication of strains of seven anaerobic species was observed. ${ }^{36}$ In strains of $P$. aeruginosa, the exposure to doripenem achieved a higher elimination when the concentration of the antibiotic was 10 times the bacterium's MIC. ${ }^{37}$ In a computerized pharmacokinetics simulation model, the exposure to doripenem, imipenem, and meropenem for two hours reduced the number of $\mathrm{CFU} / \mathrm{mL}$ more than $2 \log _{10}$, while ceftazidime only achieved a similar reduction with an exposure of over four hours. Experimental models have yielded similar results. ${ }^{28}$

\section{Pharmacokinetic/pharmacodynamic parameters}

The integration of pharmacokinetic/pharmacodynamic parameters (PK/PD) derived from nonclinical models with pharmacokinetic data from phase I studies may be useful for the purpose of optimizing antibiotic dosage regimens in phase II and III studies. ${ }^{38}$ In the case of doripenem, one study $^{39}$ used the PK/PD parameters obtained in another study with a mouse-thigh infection model, in which the mean value of parameter T > MIC associated with $1 \log _{10}$ and $2 \log _{10}$ reductions in CFU/thigh were $21.1 \pm 8.9 \%$ and $27.3 \pm 11.9 \%$ for strains of $S$. pneumoniae, $32.3 \pm 6.7 \%$ and $35.4 \pm 5.0 \%$ 
for strains of $S$. aureus, and $36.1 \pm 7.4 \%$ and $43.3 \pm 7.1 \%$ for Gram-negative bacilli, respectively. ${ }^{40}$ Additionally, by using the pharmacokinetic data from phase I studies, and applying the Monte Carlo simulation, the probability of obtaining a $\mathrm{T}>\mathrm{MIC}$ over $35 \%$ was determined for different dosage regimens of doripenem (doses of 250, 500, 750, 1,000, 2,000, and 3,000 mg; intervals of 6, 8, 12, and 24 hours, and duration of infusion of 1 to 6 hours, and 24 hours). According to the results, when the MIC was $1 \mathrm{mg} / \mathrm{L}$, the probability of obtaining a $\mathrm{T}>\mathrm{MIC}$ of $35 \%$ was observed with all the doses studied (250-1,000 mg) administered every eight hours, irrespective of the duration of the infusion. On the other hand, when the MIC was $2 \mathrm{mg} / \mathrm{L}$, the probability of obtaining the objective value of the PK/PD parameter was similar with doses of $500 \mathrm{mg}$ or higher administered every eight hours in one-hour infusions. A regimen of $500 \mathrm{mg}$ every eight hours in one-, two-, and three-hour infusions resulted in a $0.99,1$, and 1 probability of obtaining a value of $\mathrm{T}>\mathrm{MIC}$ of $35 \%$, respectively. Finally, when MIC was 4 or $8 \mathrm{mg} / \mathrm{L}$, the probability of obtaining a $\mathrm{T}>\mathrm{MIC}$ of $35 \%$ was higher when the same daily doses of doripenem were used, but over a longer infusion time. When MIC was $4 \mathrm{mg} / \mathrm{L}$ a regimen of $500 \mathrm{mg}$ every eight hours in three-, four- or five-hour infusions resulted in a 1,1 , and 0,99 probability of obtaining a $\mathrm{T}>\mathrm{MIC}$ of $35 \%$, respectively. Similarly, a regimen of $1,000 \mathrm{mg}$ every 12 hours in four-, five- or six-hour infusions resulted in a probability of obtaining a $\mathrm{T}>\mathrm{MIC}$ of $35 \%$ of 1 in all cases. Additionally, a regimen of 1,000 mg every eight hours in one-, two- or three-hour infusions resulted in a probability of obtaining a $\mathrm{T}>\mathrm{MIC}$ of $35 \%$ of $0.99,1$, and 1 , respectively. Finally, a regimen of $1,000 \mathrm{mg}$ every 24 hours in 24-hour infusion led to a probability of 0 , but 2,000 $\mathrm{mg}$ or 3,000 $\mathrm{mg}$ led to a probability of obtaining a $\mathrm{T}>\mathrm{MIC}$ of $35 \%$ of 0,98 and 1 , respectively. On the other hand, when $\mathrm{MIC}$ was $8 \mathrm{mg} / \mathrm{L}$, a regimen of 1,000 $\mathrm{mg}$ every eight hours in three-, four- or five-hour infusions resulted in 1, 1, and 0.99 probability of obtaining a $\mathrm{T}>\mathrm{MIC}$ of $35 \%$, respectively. However, a regimen of $1,000,2,000$ or $3,000 \mathrm{mg}$ every 24 hours in 24-hour infusion led to a $0,0,0,46$ probability of obtaining a $\mathrm{T}>\mathrm{MIC}$ of $35 \%$, respectively.

Thus, by prolonging the infusion time, the administration of similar doses may be effective in the treatment of microorganisms with different doripenem's MICs.

Similarly to the study above, another study with a mouse-thigh infection model with strains of $P$. aeruginosa used the doripenem dosages that allowed an approximation to the $\mathrm{T}>\mathrm{MIC}$ simulated in human beings, based on pharmacokinetic parameters from 24 healthy individuals ${ }^{1}$ after the administration of $500 \mathrm{mg}$ every eight hours, either in a one-hour or a four-hour infusion. ${ }^{41}$ By administering the antibiotic in a one-hour infusion, the achieved reduction in the bacterial load was approximately $3 \log _{10} \mathrm{CFU} / \mathrm{mL}$ when the MIC was between $0.125 \mathrm{mg} / \mathrm{L}$ and $2 \mathrm{mg} / \mathrm{L}$, with a T $>$ MIC between $42.5 \%$ and $100 \%$; the results varied widely when the MIC was $4 \mathrm{mg} / \mathrm{L}$ or $8 \mathrm{mg} / \mathrm{L}$, with $\mathrm{T}>\mathrm{MIC}$ values of $20 \%$ and $30 \%$, respectively. Thus, bacterial growth was observed in two of the eight strains that showed these MIC values, one of $4 \mathrm{mg} / \mathrm{L}$, and the other of $8 \mathrm{mg} / \mathrm{L}$. Finally, bacterial growth was observed in the strains with a MIC of $16 \mathrm{mg} / \mathrm{L}$, with a $\mathrm{T}>\mathrm{MIC}$ value of $10 \%$. On the other hand, by administering the antibiotic in a four-hour infusion, the efficacy obtained was similar to that observed with the one-hour administration, when the MIC was $2 \mathrm{mg} / \mathrm{L}$, with a T > MIC value between $42.5 \%$ and $70 \%$. Surprisingly, the bacterial growth observed was of approximately $1 \log _{10} \mathrm{CFU} / \mathrm{mL}$ in two of the four strains with a MIC of $4 \mathrm{mg} / \mathrm{L}$, with a T $>$ MIC value of $52.5 \%$, an unexpected result. However, the decrease in the bacterial load observed in the two remaining strains was -1.5 to $-2.5 \log _{10} \mathrm{CFU} / \mathrm{mL}$, with a $\mathrm{T}>\mathrm{MIC}$ similar to that of the other two strains, ie, $52.5 \%$. This decrease was greater than that observed with a one-hour infusion. Finally, a global growth was observed in the bacterial density when the MIC was between 8 and $16 \mathrm{mg} / \mathrm{L}$, but MIC was not surpassed at any time $(\mathrm{T}>\mathrm{MIC}=0 \%)$. Thus, exposure to $\mathrm{T}>\mathrm{MIC}$ values $\geq 40 \%$ resulted in a more effective bactericidal activity, while values of this parameter between $20 \%$ and $30 \%$ led to more variable results. Similar values for the $\mathrm{T}>\mathrm{MIC}$ parameter of doripenem were reported in a study that used an in vitro PK/PD against three strains of P. aeruginosa. ${ }^{42}$ Thus, steady state was reached with values of this index of $25 \%, 23.9 \%$, and $39.8 \%$ for each of the strains, a bacterial eradication of $2 \log \mathrm{CFU} / \mathrm{mL}$ was obtained with values of $28.1 \%, 29.5 \%$, and $49.6 \%$, and $90 \%$ of maximum bacterial eradication was obtained with $\mathrm{T}>\mathrm{MIC}$ values of $36.5 \%, 46.8 \%$, and $80.7 \%$. This study, along with a prior study that used a pharmacodynamic model for analyzing bactericidal kinetic parameters in vitro, ${ }^{43}$ did not take into account the possible role of certain factors that appear only in vivo and which may affect the antimicrobial agent's activity, such as the immune system. With the purpose of attenuating this limitation, another study used a simulation strategy and a PK/PD model to simulate doripenem's, imipenem's, and meropenem's bactericidal profile in a murine model of $P$. aeruginosa lung infection. ${ }^{44}$ The results showed a good estimation of the bacterial eradication curves obtained by the model when applied to animals, which may be useful in the future design of therapeutically useful dosage regimens. 
The results of another study with 100 strains of $P$. aeruginosa showed a higher probability of reaching a $\mathrm{T}>\mathrm{MIC}$ value of $25 \%$ ( $\mathrm{T}>$ MIC $25 \%$ ) and $40 \%$ ( $\mathrm{T}>\mathrm{MIC} 40 \%$ ) with doripenem vs imipenem and meropenem, regardless of the dosage regimen used. ${ }^{45}$ Thus, the probability of achieving the $\mathrm{T}>$ MIC $25 \%$ and $\mathrm{T}>$ MIC $40 \%$ for doripenem with the $500 \mathrm{mg}$ every eight hours in a half-hour infusion regimen was $77.2 \%$ and $54.9 \%$, respectively, when the dilution method used to obtain the MIC was the serial twofold dilution method; these values were $80.2 \%$ and $54.7 \%$ respectively, when an integrated concentration method was used to obtain the MIC. Similarly, the probability of obtaining T > MIC 25\% and $\mathrm{T}>$ MIC $40 \%$ for doripenem with the $250 \mathrm{mg}$ every eight hours in a half-hour infusion scheme was $60.6 \%$ and $37.4 \%$, respectively, when the dilution method used to obtain the MIC was the serial twofold dilution method, while these values were $60.4 \%$ and $36.8 \%$, respectively, when an integrated concentration method was used. Population pharmacokinetic modeling was conducted using drug concentration data in plasma and urine from 18 patients with urinary tract infection and prostatitis. ${ }^{46}$ Based on this pharmacokinetic model, a Monte Carlo simulation predicted the probabilities of attaining T $>$ MIC $40 \%$ in plasma and defined the PK/PD breakpoints. The highest MIC at which the probability of target attainment in plasma was $\geq 90 \%$ varied with creatinine clearance (CL) and doripenem regimen. The value for $500 \mathrm{mg}$ every eight hours with a creatinine $\mathrm{CL}$ of $80 \mathrm{~mL} / \mathrm{min}$ corresponded to those for $250 \mathrm{mg}$ every eight hours with a creatinine $\mathrm{CL}$ of $40 \mathrm{~mL} / \mathrm{min}$ and $250 \mathrm{mg}$ every 12 hours with a creatinine $\mathrm{CL}$ of $20 \mathrm{~mL} / \mathrm{min}$, all of them administered in one-hour infusion. The aim of a recent study was to analyze the urinary bactericidal titers (UBTs) and 24-hour area under the UBT-versus-time curve (AUBT) of intravenous doripenem (500 mg every eight hours) versus those of intravenous levofloxacin (250 mg every 24 hours) in patients with complicated urinary tract infections or pyelonephritis. ${ }^{47}$ For the selected clinical strains, median UBTs and median 24-hours AUBTs of doripenem ranged between 1.5 and 65,536 and between 224 and 909,312, respectively. These values were significantly higher than those of levofloxacin, with the exception of $S$. aureus 1134684 (median UBTs 0-128, median 24-hour AUBTs 0-2,208). Eight microbiological failures were observed, three after doripenem treatment and five after levofloxacin treatment. In the levofloxacin group, microbiological failures were observed only in patients with AUBT values of 152 or lower, whereas no correlation between treatment failure and AUBT level was found in the doripenem group.
The clinical safety and efficacy of some of the dosing regimens have been confirmed in phase III clinical trials. ${ }^{48}$ However, phase III clinical trials of doripenem in hospitalacquired pneumonia at a dose of $1,000 \mathrm{mg}$ infused over four hours every eight hours are undergoing clinical evaluation.

\section{Pharmacokinetic profile Distribution}

The administration of a single $500 \mathrm{mg}$ dose of doripenem to 24 healthy subjects by intravenous infusion over one hour was associated with a mean maximum concentration (Cmax) of $23 \pm 6.6 \mu \mathrm{g} / \mathrm{mL}$ and an AUC of $36.3 \pm 8.8 \mu \mathrm{g} \cdot \mathrm{h} / \mathrm{mL} .{ }^{1}$ In another study, the administration of a single $500 \mathrm{mg}$ dose of radiolabeled doripenem to eight healthy individuals in a one-hour infusion produced a Cmax of $22.9 \pm 2.37 \mu \mathrm{g} / \mathrm{mL}$, which was reached in a period (Tmax) of 1.02 hours. ${ }^{26}$ Also, $\mathrm{AUC}_{0-\infty}$ was $31.8 \pm 4.50 \mu \mathrm{g} \cdot \mathrm{h} / \mathrm{mL}$. Doripenem was the main plasma component, and represented $80.7 \%$ of the $\mathrm{AUC}_{0-\infty}$ for total plasma radioactivity.

The binding of doripenem to plasma proteins is estimated to be $8.1 \%$, regardless of the plasma concentrations obtained. ${ }^{1}$ The mean distribution volume is $16.8 \mathrm{~L}$ (range: 8.09-55.5) in healthy individuals once steady state has been reached; this value is similar to the extracellular fluid volume $(18.2 \mathrm{~L})$.

The administration of doripenem to 10 abdominal surgery patients yielded an $\mathrm{AUC}_{0-\infty}$ of $59.3 \pm 7.2 \mathrm{mg} \cdot \mathrm{h} / \mathrm{L}$ in serum, and of $49.3 \pm 6.5 \mathrm{mg} \cdot \mathrm{h} / \mathrm{L}$ in peritoneal exudate, with a ratio of $\mathrm{AUC}_{0-\infty}$ exudate/AUC $\mathrm{AU}_{0-\infty}$ serum of $0.84 \pm 0.13 .{ }^{49}$ Despite these values, $\mathrm{T}>\mathrm{MIC}$ yielded a slightly higher value in peritoneal exudate compared to serum, but significant differences were seen only when the MIC was 1 or $4 \mathrm{mg} / \mathrm{L}$. Thus, $\mathrm{T}>\mathrm{MIC}$ in the exudate compared to that in serum was $78.2 \pm 10.6 \%$ vs $73.6 \pm 12 \%$, respectively when the MIC was $1 \mathrm{mg} / \mathrm{L} ; 41.5 \pm 7.3 \%$ vs $37.0 \pm 6.3 \%$ respectively, for a MIC of $4 \mathrm{mg} / \mathrm{L}$; and $13.1 \pm 4.0 \%$ vs $12.7 \pm 1.7 \%$ respectively, for a MIC of $16 \mathrm{mg} / \mathrm{L}$. This fact may be explained by the small difference (only 0.2 hours) observed in reaching the Tmax in both compartments; for this reason it has been thought that the concentration in the exudate would be higher than in serum once 0.81 hours had elapsed after administration. In addition to the peritoneal level, doripenem has also shown an ability to penetrate other tissues and/or fluids, according to studies in animal models (Table 6)..$^{50}$

\section{Metabolism and excretion}

Doripenem-M-1, which has a dicarboxylic acid structure, is doripenem's main metabolite, but three additional metabolites 
Table 6 Plasma and different tissues concentrations following the administration of $500 \mathrm{mg}$ of doripenem

\begin{tabular}{llllllll}
\hline Antibiotic & Time $(\mathrm{min})$ & Plasma $(\mu \mathrm{g} / \mathrm{mL})$ & Liver $(\mu \mathrm{g} / \mathrm{g})$ & Kidney $(\mu \mathrm{g} / \mathrm{g})$ & Lung $(\mu \mathrm{g} / \mathrm{g})$ & Spleen $(\mu \mathrm{g} / \mathrm{g})$ & Heart $(\mu \mathrm{g} / \mathrm{g})$ \\
\hline Doripenem & 5 & $46.9 \pm 2.3$ & $14.5 \pm 1.1$ & $42.2 \pm 6.6$ & $11.3 \pm 2.5$ & $5.71 \pm 0.86$ & $7.77 \pm 0.33$ \\
& 15 & $16.9 \pm 3.7$ & $14.8 \pm 2.9$ & $16.4 \pm 1.8$ & $3.47 \pm 0.43$ & 0.99 & $2.52 \pm 0.19$ \\
& 60 & $0.97 \pm 0.18$ & $2.04 \pm 1.19$ & 0.80 & ND & ND & ND \\
\hline
\end{tabular}

Notes: Adapted from Hori T, Nakano M, Kimura Y, Murakami K. Pharmacokinetics and tissue penetration of a new carbapenem, doripenem, intravenously administered to laboratory animals. In Vivo. 2006; 20(I):91-96.

Abbreviation: ND, not detected.

have been identified: the glycine- and taurine-conjugates of doripenem-M-1, and the oxidized metabolite of doripenem-M-1 . However, these three derivates represented less than $3 \%$ when a single $500-\mathrm{mg}$ dose of doripenem was administered to healthy individuals. ${ }^{51}$ Doripenem-M-1's Cmax and $\mathrm{AUC}_{0-\infty}$ were $1.56 \pm 0.24 \mu \mathrm{g} / \mathrm{mL}$ and $4.98 \pm 0.389 \mu \mathrm{g} \cdot \mathrm{h} / \mathrm{mL}$ on average, which represent $6.8 \%$ and $15.7 \%$ of doripenem's Cmax and $\mathrm{AUC}_{0-\infty}$, while $\mathrm{t} 1 / 2$ was $2.54 \pm 0.264$ hours. In a study using radiolabeling, doripenem-M-1 contributed $12.7 \%$ of the $\mathrm{AUC}_{0-\infty}$ plasma total-radioactivity. Additionally, the percentage of doripenem-M-1's AUC compared to doripenem's AUC was $18 \pm 7.2 \%$ following the administration of a single dose of $500 \mathrm{mg}$ or $1 \mathrm{~g}$ to healthy individuals. ${ }^{1}$

Table 7 shows several pharmacokinetic parameters of doripenem in healthy patients and in patients undergoing abdominal surgery. The elevated CL, along with the reduction in excretion of the carbapenem after administration with probenecid, suggests that doripenem undergoes both glomerular filtration and active tubular secretion. Approximately $70 \%$ of the antibiotic was excreted unchanged in urine within 48 hours after administration of a single 500 -mg dose to healthy individuals, while $15 \%$ was excreted as a metabolite. ${ }^{1}$ In another study, $93.4 \%$ and $95.3 \%$ of radioactivity was recovered in urine during the first 12 hours and at seven days, respectively, following the administration of a single 500-mg dose of radiolabeled doripenem in a one-hour infusion to eight healthy individuals. ${ }^{51}$ On the other hand, fecal excretion of doripenem was also observed, but it represented only $0.72 \%$ of the dose administered. Additionally, the total amount of drug excreted in urine (Ae) was $394.1 \mathrm{mg}$ seven days after administration for doripenem, which represented $78.7 \%$ of the dose, while the Ae for doripenem-M-1 was $92.9 \mathrm{mg}$, which represented $18.5 \%$ of the dose. A total of $487 \mathrm{mg}(97.2 \%)$ of the administered dose of doripenem was recovered in urine, either unchanged or as doripenem-M-1. Despite the fact that recovery in urine was complete during the first 24 hours after administering the dose, excretion occurred mostly during the first four hours. Renal CL of doripenem and doripenem-M-1 was $12.5 \mathrm{~L} / \mathrm{h}$ and $18.9 \mathrm{~L} / \mathrm{h}$, respectively.

Table 7 Pharmacokinetic characteristics of doripenem in healthy patients and in patients who underwent abdominal surgery

\begin{tabular}{|c|c|c|c|}
\hline Dosage regimen & $\begin{array}{l}500 \mathrm{mg} \text { single } \\
\text { dose }\end{array}$ & $\begin{array}{l}500 \mathrm{mg} \text { single } \\
\text { dose }\end{array}$ & $\begin{array}{l}500 \mathrm{mg} \text { pre-surgery } \\
\text { and } 500 \mathrm{mg} / 8 \mathrm{~h} \text { post-surgery }\end{array}$ \\
\hline Infusion time (h) & I & 1 & 0.5 \\
\hline Study population & 24 healthy subjects & 8 healthy subjects & $\begin{array}{l}10 \text { patients who underwent } \\
\text { abdominal surgery }\end{array}$ \\
\hline $\mathrm{Cmax}(\mu \mathrm{g} / \mathrm{mL})$ & $23 \pm 6.6$ & $22.9 \pm 2.37$ & $46.9 \pm 7.4$ \\
\hline $\operatorname{Tmax}(\mathrm{h})$ & - & $1.02(1.00-1.02)$ & 0.5 \\
\hline $\mathrm{AUC}(\mu \mathrm{g} \cdot \mathrm{h} / \mathrm{mL})$ & $36.3 \pm 8.8$ & $31.8 \pm 4.50$ & $59.3 \pm 7.2$ \\
\hline PPB (\%) & $8.1 \%$ & - & - \\
\hline Vss (L) & I $6.8(8.09-55.5)$ & $24.8 \pm 5.80$ & $11.0 \pm 1.7$ \\
\hline $\mathrm{t}_{\mathrm{I} / 2}(\mathrm{~h})$ & I & $1.07 \pm 0.125$ & - \\
\hline Kidney $\mathrm{Cl}(\mathrm{L} / \mathrm{h})$ & $10.8 \pm 3.5$ & 12.5 & - \\
\hline Total Cl (L/h) & $15.9 \pm 5.3$ & $16 \pm 2.23$ & $8.56 \pm 1.14$ \\
\hline
\end{tabular}

Notes: Data from Doribax ${ }^{\circledR}$ (doripenem for injection) package insert, ' Cirillo et al, ${ }^{51,52}$ Ikawa et al. ${ }^{49}$

Abbreviations: AUC, area under the curve; $\mathrm{Cl}$, clearance; $\mathrm{Cmax}$, maximum concentration; PPB (\%), plasma protein binding; $\mathrm{t}_{1 / 2}$, serum half-life; Tmax, time to maximum concentration; Vss, volume of distribution in steady state. 


\section{Special populations}

No safety and efficacy data are available for pediatric patients and for this reason use is not recommended in this population.

In patients over 66 years of age, the mean AUC was $49 \%$ higher than in nonelderly adults. ${ }^{1}$ These differences were attributed to age-related changes in renal CL. On the other hand, no differences were observed in the AUC or in the Cmax in terms of the gender of the subjects. Furthermore, doripenem's pharmacokinetics does not seem to be affected by the degree of hepatic impairment. ${ }^{1}$ Hispanics/Latins had a CL 14\% higher than Caucasian individuals. However, no differences were observed with respect to patients of African American, or Japanese descent.

\section{Renal impairment}

Following a single 500-mg dose of doripenem in patients with mild (renal CL 50-79 $\mathrm{mL} / \mathrm{min}$ ), moderate (renal CL $31-50 \mathrm{~mL} / \mathrm{min}$ ), severe (renal CL $\leq 30 \mathrm{~mL} / \mathrm{min}$ ), or endstage renal impairment, the mean AUC was 1.6, 2.8, 5,1, and 7.8 times that of healthy subjects with normal renal function. ${ }^{1}$ Therefore, dosage adjustment of the antibiotic is necessary in patients with a renal CL of $50 \mathrm{~mL} / \mathrm{min}$ or less. Following a four-hour hemodialysis in patients with end-stage renal failure who had received a single 500-mg dose of doripenem, $231 \mathrm{mg}$ of the carbapenem and $28 \mathrm{mg}$ of its metabolite were recovered. Despite the fact that, according to these data, $52 \%$ of doripenem was recovered in the dialysate, there is insufficient information to make dose-adjustment recommendations for patients on hemodialysis. ${ }^{52}$

\section{Potential drug interactions}

Similarly to other carbapenems, one of the most widely described drug interaction is that with valproic acid (VA). This fact has become evident due to the large number of reports of seizures after introducing a carbapenem in patients on stable treatment with this antiepilepsy drug. This situation has also been observed with doripenem in animal studies. ${ }^{53}$ However, in another study with an animal model, the administration of doripenem had no effect on the anticonvulsant activity obtained after administering VA in rats with pentilenetetrazolor bicuculline-induced seizures. ${ }^{54}$

Another widely reported drug interaction is that with probenecid, which results in a considerable increase in the plasma concentrations of doripenem caused by the inhibition of renal tubular secretion. ${ }^{1}$ Thus, doripenem's AUC and $t_{1 / 2}$ increased by $75 \%$ and $53 \%$ respectively when coadministered with probenecid. ${ }^{1}$ Other studies have suggested that the combination of carbapenems with vancomycin or teicoplanin might improve the antibiotic's effectiveness against infections with strains of MRSA. ${ }^{55}$ Thus, the administration of doripenem, panipenem, meropenem, or imipenem was synergistic to vancomycin and teicoplanin against more than $92 \%$ and $74 \%$ of 27 strains of MRSA from blood cultures. Specifically, the combination of doripenem with vancomycin was synergistic against $21(77.8 \%)$ strains, while the combination with teicoplanin was synergistic against 25 (92.6\%) strains.

\section{Stability and compatibility}

In an in vitro study doripenem constituted with water $(500 \mathrm{mg} / 10 \mathrm{~mL})$ retained its potency for $\geq 60$ minutes under room conditions without significant loss of its labeled potency. ${ }^{56}$ The $0.9 \%$ sodium chloride injection solution $(5 \mathrm{mg} / \mathrm{mL}$ ) retained its potency for 12 hours in room conditions and 72 hours in refrigeration. The 5\% dextrose injection solution retained its potency for four hours in room conditions and 48 hours in refrigeration. The physical compatibility of doripenem diluted for infusion in dextrose $5 \%$ injection or $0.9 \%$ sodium chloride injection during simulated Y-site administration with 82 other drugs was evaluated. ${ }^{57}$ Doripenem $5 \mathrm{mg} / \mathrm{mL}$ in $5 \%$ dextrose injection and in $0.9 \%$ sodium chloride injection was found to be compatible with 75/82 (91.5\%) of drugs tested for at least four hours. However, these solutions were incompatible with diazepam, potassium phosphates, and undiluted propofol. Doripenem $5 \mathrm{mg} / \mathrm{mL}$ in $0.9 \%$ sodium chloride injection but not in 5\% dextrose injection was incompatible with amphotericin B-containing drugs.

\section{Clinical efficacy}

The clinical trials conducted in the various phases of pre-clinical research have focused on the treatment of nosocomial pneumonia (including ventilator-associated pneumonia), complicated intra-abdominal infections, and complicated urinary tract infections, including pyelonephritis. The results of various clinical trials are described below.

\section{Nosocomial pneumonia}

Two studies have so far been published that include mostly patients with ventilator-associated pneumonia. ${ }^{58,59}$ The first study was designed with the objective of establishing that doripenem is not inferior to piperacillin/tazobactam for the treatment of nosocomial pneumonia. ${ }^{58}$ It was a prospective, multicenter, randomized, open-label, phase III study that included 448 adult patients diagnosed with nosocomial 
pneumonia and early ventilator-associated pneumonia ( $<5$ days on mechanical ventilation). Patients were stratified according to the kind of ventilation (spontaneous vs mechanical), APACHE II score, and geographic area. In the study group, patients received $500 \mathrm{mg}$ of doripenem intravenously every eight hours by one-hour infusion; subjects in the control group received piperacillin/tazobactam, $4.5 \mathrm{~g}$ every six hours by 30 -minute infusion. In both groups patients were allowed to switch to oral levofloxacin, $750 \mathrm{mg}$ every 24 hours, after 72 hours of intravenous treatment. In cases where $P$. aeruginosa was suspected, the simultaneous administration of aminoglycosides was allowed. The duration of the treatment was 7 to 14 days, depending on clinical progress. The assessment of the clinical response was done 7 to 14 days after completing the study treatment. Doripenem was not inferior to piperacillin/tazobactam because in the group of clinically evaluable patients (253 patients) there were no differences between those treated with doripenem and those treated with piperacillin/tazobactam $(81.3 \%$ vs $79.8 \%$, respectively), just like among the intent-to-treat population $(69.6 \%$ vs $64.1 \%$, respectively). However, piperacillin/tazobactam showed a rate of resistance of $44 \%$ and $26.9 \%$ against Klebsiella pneumoniae and $P$. aeruginosa isolates, respectively, while the resistance to doripenem (MIC $>8 \mu \mathrm{g} / \mathrm{mL}$ ) was of $0 \%$ and $7.7 \%$ against these bacteria. Similarly, the rates of eradication of pathogens responsible for nosocomial pneumonia were higher in the doripenem arm than in the piperacillin/tazobactam arm, although the difference was not significant. ${ }^{58}$ There were also no differences in the adverse effects associated with the study medication, which was $16.1 \%$ and $17.6 \%$ in both groups. In another prospective, multicenter, randomized, open-label, phase III study, doripenem was compared to imipenem in terms of efficacy and tolerability, for the treatment of ventilator-associated pneumonia. ${ }^{59}$ The objective was to determine the noninferiority (differences of less than $20 \%$ ) of doripenem with respect to imipenem for the treatment of this infection. Five hundred thirty-one patients from intensive care units with clinical and radiological signs of ventilator-associated pneumonia were included. The patients were stratified according to duration of the mechanical ventilation prior to pneumonia ( $<5$ days or $>5$ days), severity according to APACHE II ( $\leq 15$ or $>15)$, and geographic region. Treatment was randomized so that the study arm received doripenem $500 \mathrm{mg}$ every eight hours by continuous infusion over four hours, and the control group received imipenem $500 \mathrm{mg}$ every six hours or $1 \mathrm{~g}$ every 8 by 30 to 60 -minute infusion. The duration of the treatment was 7 to 14 days, depending on clinical progress. The clinical efficacy was established at the end of the treatment in the modified intent-to-treat population and in the clinically evaluable population. The clinical cure rates at the end of the treatment were $68.3 \%$ for doripenem, and $64.2 \%$ for imipenem in the clinically evaluable population, and $59.0 \%$ and $57.8 \%$, respectively, in the modified intent-to-treat population. In patients with ventilator-associated pneumonia caused by $P$. aeruginosa, the rates of cure were $80 \%$ for those treated with doripenem, and $42.9 \%$ for those who received imipenem (p:NS). Similarly, microbiological eradication was $65.0 \%$ and $35.7 \%$ for each of the treatment arms. In cases with $P$. aeruginosa, five of the $28(18 \%)$ of those treated with doripenem were resistant to this antibiotic, while 16 of the 25 (64\%) of those treated with imipenem were resistant to the antibiotic. The cure rates were higher in patients with a higher APACHE II score and in those who were older. In the modified intent-to-treat population, the presence of $20(8 \%)$ emergent pathogens was detected in the doripenem group, and 28 (11\%) were detected in the imipenem group; in both groups, P. aeruginosa and K. pneumoniae were the most prevalent pathogens. There were no differences between the two groups in global mortality ( $10.8 \%$ for those treated with doripenem, and $9.5 \%$ for those with imipenem). The Kaplan-Meier analysis did not show differences between both treatment groups in the cumulative mortality rate. Among the main limitations in pneumonia studies should be emphasized a limited specificity of clinical criteria in diagnosis of ventilator-associated pneumonia, the need of differentiate early ventilator-associated pneumonia versus late ventilator-associated pneumonia and the heterogeneous distribution of combined therapy with aminoglycosides between groups. ${ }^{60}$

\section{Complicated intra-abdominal infections}

A prospective, multicenter, double-blind, randomized study compared the efficacy and tolerability of doripenem versus meropenem for the treatment of complicated intraabdominal infections in hospitalized adults. ${ }^{61}$ The objective of the study was to show the non-inferiority (less than $15 \%$ of difference in clinical cure rate) of doripenem for the treatment of these infections compared to meropenem. Patients were randomized to receive doripenem, $0.5 \mathrm{~g}$ every eight hours in a one-hour infusion, or meropenem, $1 \mathrm{~g}$ every eight hours in bolus over 3-5 minutes. In both study arms the association with vancomycin was allowed when there was a known or suspected presence of Enterococcus spp. or a methicillin-resistant Staphylococcus. The treatment could be switched to amoxicillin/clavulanic acid (875/125 mg 
every eight hours), after having received nine doses of the study treatment (three days), only if progress was favorable. Treatment was maintained between 5 and 14 days depending on clinical progress. Four hundred seventy-six patients were included, who had complicated appendicitis or other complicated intra-abdominal infection, including bowel perforation, cholecystitis, intra-abdominal abscess, solid organ abscess, and generalized peritonitis. The main evaluation criterion was the clinical cure rate in microbiologically evaluable patients, which was done in the visit between 21 and 60 days after completing treatment. The cure rate in the 319 microbiologically evaluable patients was $85.9 \%$ among those treated with doripenem, and 85.3\% among those treated with meropenem; no other difference was found in the different population subgroups analyzed. In the intent-to-treat population, severe adverse reactions were found in $13.2 \%$ and $14.0 \%$ of both groups; this caused the discontinuation of the drug in $5.1 \%$ and $2.1 \%$ of the cases, respectively. Nor were differences observed in the mortality rate, which was very low in both groups $(2.1 \%$ vs $3.0 \%)$. The main limitation of this study was the small sample of patients who developed postoperative infections in both groups. A second, not yet published, study, ${ }^{9}$ conducted with a design identical to the one described above, included 466 patients with complicated intra-abdominal infection. The cure rate in the microbiologically evaluable population was $83.3 \%$ and $83.0 \%$ for doripenem and meropenem, respectively. ${ }^{1}$

\section{Complicated urinary tract infections}

Clinical experience with this kind of infection is based on two yet unpublished prospective, multicenter, randomized studies ${ }^{9}$ that included 1,179 patients. ${ }^{1}$ One of the studies was double-blind, and compared the administration of doripenem, $500 \mathrm{mg}$ every eight hours by continuous infusion over one hour, to levofloxacin, $250 \mathrm{mg}$ intravenously. Both studies allowed the option to switch to oral levofloxacin, $250 \mathrm{mg}$ every 24 hours after the intravenous administration of the study drugs for three days. The maximum duration of the treatment was established in 10 days. Patients with concurrent bacteremia were treated with $500 \mathrm{mg}$ of levofloxacin (both intravenously and orally), and the treatment was maintained for 10 to 14 days. Cure rates in the microbiologically evaluable population (isolation of pathogens in the baseline cultures) on the visit between the 5th and 11th day after completing treatment was $82.1 \%$ in those treated with doripenem, and $83.4 \%$ in those treated with levofloxacin. The rates of eradication of pathogens responsible for the infections were high, and similar in both treatments for most evaluated microorganisms.

Low dose of levofloxacin employed in this study may represent a limitation to extrapolate the results in areas with high rate of quinolone resistance. The introduction of switch therapy from intravenous to oral route constitutes an additional limitation in order to evaluate both efficacy and safety.

\section{Tolerability}

Doripenem's tolerability profile has been extensively studied in various trials. According to the results, doripenem is a well tolerated antibiotic, and has been associated with a low incidence of gastrointestinal or central nervous system adverse events. Imipenem is the carbapenem most often associated with a high risk of seizures, but doripenem, meropenem, and ertapenem do not seem to have such a close association, as several animal model studies have shown. ${ }^{54,62}$

One of the most commonly adverse effect reported in studies evaluating doripenem is headache, in 33\% and 50\% of patients receiving $500 \mathrm{mg}$ every eight hours and $1000 \mathrm{mg}$ every eight hours, respectively, vs $13 \%$ of controls. ${ }^{63}$ Also, some gastrointestinal effects such as nausea and diarrhea have been reported in $3.7 \%$ and $2.5 \%$ of patients, respectively. ${ }^{64}$ Additionally, the adverse events described in another study were mild, and included headache, dyspepsia, and erythema at the site of administration. ${ }^{65}$ The only laboratory abnormality reported was a moderate elevation of transaminases.

Three out of eight healthy volunteers included in one study experienced adverse effects following the administration of a single dose of $500 \mathrm{mg}$ of doripenem. ${ }^{51}$ One of the subjects had diarrhea, another experienced flatulence, and the third had vertigo; however only the first two cases were related to the antimicrobial agent. The incidence and type of the adverse events were similar in patients with ventilatorassociated pneumonia who received either imipenem $500 \mathrm{mg}$ every six hours or $1000 \mathrm{mg}$ every eight hours by 30 - or 60-minute continuous infusion, or doripenem $500 \mathrm{mg}$ every eight hours in a four-hour intravenous infusion, for a period of 7 to 14 days. $^{59}$ Thus, $17.5 \%$ of 263 patients, and $17.2 \%$ of 262 patients receiving imipenem or doripenem treatment, respectively, experienced at least one adverse event (Table 8). Discontinuation of treatment occurred in $6 \%$ of patients in each group. Only four and five adverse events in the imipenem or doripenem groups, respectively, were related to the antibiotic given. Additionally, 3.8\% of patients receiving imipenem had seizures, while this event occurred in $1.1 \%$ of those receiving doripenem. However, in 
Table 8 Antibiotic-related adverse events observed in at least $1 \%$ of patients in each treatment group

\begin{tabular}{|c|c|c|c|c|}
\hline \multirow[t]{3}{*}{ Adverse event } & \multicolumn{2}{|c|}{ Nosocomial pneumonia } & \multirow{2}{*}{\multicolumn{2}{|c|}{$\begin{array}{l}\text { Ventilator-associated pneumonia } \\
\text { Chastre et al } 2008^{59}\end{array}$}} \\
\hline & \multicolumn{2}{|c|}{ Réa-Neto et al $2008^{58}$} & & \\
\hline & $\begin{array}{l}\text { Doripenem } \\
(n=223) n(\%)\end{array}$ & $\begin{array}{l}\text { Piperacillin/tazobactam } \\
(n=221) n(\%)\end{array}$ & $\begin{array}{l}\text { Doripenem } \\
(n=262) n(\%)\end{array}$ & $\begin{array}{l}\text { Imipenem } \\
(n=263) n(\%)\end{array}$ \\
\hline $\begin{array}{l}\text { Patients with at least one } \\
\text { antibiotic-related adverse event }\end{array}$ & $36(16.1)$ & $39(17.6)$ & $45(17.2)$ & $46(17.5)$ \\
\hline Elevated liver enzymes & - & - & $12(4.6)$ & $6(2.3)$ \\
\hline Elevated gamma-glutamyltransferase & $6(2.7)$ & $4(1.8)$ & - & - \\
\hline Elevated alanine aminotransferase & $4(1.8)$ & $2(0.9)$ & - & - \\
\hline Diarrhea & $4(1.8)$ & $5(2.3)$ & $5(1.9)$ & $8(3.0)$ \\
\hline Rash & - & - & $5(1.9)$ & $2(0.8)$ \\
\hline Thrombocytemia & $4(1.8)$ & $5(2.3)$ & & \\
\hline Vomiting & - & - & $4(1.5)$ & $2(0.8)$ \\
\hline Phlebitis & $3(1.3)$ & $2(0.9)$ & & \\
\hline Elevated aspartate aminotransferase & $3(1.3)$ & $I(0.5)$ & & \\
\hline Elevated eosinophil count & $3(1.3)$ & $\mathrm{I}(0.5)$ & & \\
\hline Nausea & - & - & $3(1.1)$ & $6(2.3)$ \\
\hline Fungal infection & - & - & $3(1.1)$ & I $(0.4 \%)$ \\
\hline Impaired liver function & - & - & $2(0.8)$ & $4(1.5)$ \\
\hline
\end{tabular}

all patients, except for one of those receiving imipenem, the seizures were not related to the study antibiotic. In another prospective, multicenter, randomized study, one of the objectives was to analyze the safety and efficacy of doripenem vs piperacillin/tazobactam in patients with nosocomial pneumonia. ${ }^{58}$ In the intent-to-treat analysis, of 223 patients who received treatment with doripenem, 67 (30\%) experienced severe adverse events, while this occurred in $58(26.2 \%)$ of the 221 patients who received piperacillin/tazobactam. However, none of the events was related to the study antimicrobial. Discontinuation of treatment due to adverse events occurred in nine (4\%) of 223 patients receiving doripenem, and in $14(6.3 \%)$ of 221 receiving piperacillin/tazobactam. The crude mortality rate was $13.8 \%(30 / 217)$ in the group of patients receiving doripenem, and $14.6 \%(31 / 212)$ in the group receiving piperacillin/tazobactam.

Study antibiotic-related adverse reactions were observed in $36(16.1 \%)$ of 223 patients receiving doripenem and in $39(17.6 \%)$ of 221 patients receiving piperacillin/tazobactam. While an elevation of gamma-glutamyltransferase was the most commonly observed adverse effect in the doripenem group $(2.7 \%)$, diarrhea $(2.3 \%)$ and/or thrombocythemia $(2.3 \%)$ occurred more often in the piperacillin/tazobactam group. Additionally, three patients of the doripenem group, and six of the piperacillin/tazobactam group had seizures. However, the seizures were not related to the study antibiotic in any of the cases.
Similarly to previous studies, another study with subjects with complicated intra-abdominal infection did not report significant differences in the number of patients who experienced adverse effects following the administration of doripenem $500 \mathrm{mg}$ in a one-hour intravenous infusion or of meropenem $1 \mathrm{~g}$ in bolus, with both antimicrobials being prescribed every eight hours. ${ }^{61}$ Thus, 195 (83\%) of the 235 patients receiving doripenem experienced some kind of adverse events, compared to 184 (78\%) of the 236 patients receiving meropenem. However, the adverse events were related to the study antimicrobial in 76 (32.3\%) patients receiving doripenem and in 63 (26.7\%) of those receiving meropenem. Among the reactions in both doripenem and in meropenem groups were nausea $(6.8 \%$ vs $1.3 \%$, respectively), and diarrhea (6.4\% vs $4.7 \%)$.

No patient had seizures as an adverse event. Treatment had to be discontinued in five $(2.1 \%)$ patients receiving doripenem, and in three $(1.3 \%)$ of those receiving meropenem, as a result of the development of adverse events related to the study antimicrobial. When the severity of the adverse events was analyzed, the number of patients who experienced severe reactions was not different in the doripenem and the meropenem groups (13.2\% vs 14\%, respectively), but none of the events was related to the study drug. The adverse events caused the death of $2.1 \%$ of patients in the doripenem group, compared to $3 \%$ of those receiving meropenem. The following tables show the adverse events related to the 
antimicrobial agent observed in $\geq 1 \%$ of the patients included in three phase III clinical trials (Table 9). ${ }^{1}$

The prevalence of hypersensitivity to carbapenems in patients who are allergic to penicillin has been described as ranging from $9.2 \%$ to $11 \%{ }^{66-68}$ In general, treatment with carbapenems may be considered in patients with a penicillin allergy not mediated by immunoglobulin $\mathrm{E}$ only if other therapeutic alternatives are not available. ${ }^{62}$ Conversely, treatment with these carbapenems should be ruled out if the patient has a positive skin test or another documented hypersensitivity to penicillin type 1 , unless the clinical circumstances justify their use.

\section{Pharmacoeconomic considerations}

Literature about the pharmacoeconomic aspects of doripenem is limited. A subanalysis ${ }^{69}$ from a randomized clinical study comparing doripenem versus imipenem in ventilatorassociated pneumonia ${ }^{59}$ assessed the use of resources by each treatment group. Both patient groups had comparable demographic, clinical, and mortality characteristics. The median hospital length of stay (LOS) was 22 (95\% confidence interval $[\mathrm{CI}]: 20-25)$ days in the doripenem group, and 27 (95\% CI: 23-30) days in the imipenem group. A comparison between the Kaplan-Meier curves showed that the patients receiving doripenem were discharged earlier than the patients receiving imipenem $(p=0.010)$. Similarly, fewer days on mechanical ventilation (MV) was observed in the group of patients with doripenem compared to the group with imipenem (median 7 [95\% CI: 6-8] days vs 10 [95\% CI: 8-11] days, respectively). This result was corroborated by Kaplan-Meier curves of the number of days on MV; doripenem was associated with a shorter stay compared to imipenem $(\mathrm{p}=0.034)$. In contrast, no differences were observed in the LOS in intensive care units (ICU) between treatment groups (median doripenem 12 [95\% CI: 11-13] days vs imipenem 13 [95\% CI: $12-15]$ ( $\mathrm{p}=0.123$ by KaplanMeier). Some differences of this study could be attributed to the fact that not all LOS was due specifically to ventilatorassociated pneumonia. Some patients with this clinical condition were admitted to the hospital for other pathologies and subsequently acquired ventilator-associated pneumonia as a result of mechanical ventilation. Additionally, an analysis was

Table 9 Study antibiotic-related adverse events observed in at least $1 \%$ of patients in each treatment group

\begin{tabular}{|c|c|c|c|c|}
\hline & \multicolumn{2}{|c|}{$\begin{array}{l}\text { Complicated urinary tract infection } \\
\text { (I trial) }\end{array}$} & \multicolumn{2}{|c|}{$\begin{array}{l}\text { Complicated intra-abdominal infection } \\
\text { ( } 2 \text { trials) }\end{array}$} \\
\hline & $\begin{array}{l}\text { Doripenem } \\
500 \text { mg every } \\
8 \text { h }(n=376)\end{array}$ & $\begin{array}{l}\text { Levofloxacin } \\
250 \mathrm{mg} \text { IV every } \\
24 \mathrm{~h}(\mathrm{n}=372)\end{array}$ & $\begin{array}{l}\text { Doripenem } \\
500 \text { mg every } \\
8 \mathrm{~h}(\mathrm{n}=477)\end{array}$ & $\begin{array}{l}\text { Meropenem I g } \\
\text { every } 8 \mathrm{~h} \\
(\mathrm{n}=469)\end{array}$ \\
\hline \multicolumn{5}{|l|}{ Nervous system } \\
\hline Headache & 16 & 15 & 4 & 5 \\
\hline \multicolumn{5}{|l|}{ Vascular disorders } \\
\hline Phlebitis & 4 & 4 & 8 & 8 \\
\hline \multicolumn{5}{|l|}{ Gastrointestinal disorders } \\
\hline Nausea & 4 & 6 & 12 & 9 \\
\hline Diarrhea & 6 & 10 & II & 11 \\
\hline \multicolumn{5}{|c|}{ Blood and lymph system disorders } \\
\hline Anemia & 2 & I & 10 & 5 \\
\hline \multicolumn{5}{|c|}{ Kidney and urinary tract disorders } \\
\hline Kidney impairment/failure & $<1$ & 0 & 1 & $<1$ \\
\hline \multicolumn{5}{|c|}{ Skin and subcutaneous tissue disorders } \\
\hline Pruritus & $<1$ & I & 3 & 2 \\
\hline Rash & I & I & 5 & 2 \\
\hline \multicolumn{5}{|l|}{ Lab tests } \\
\hline Elevated liver enzymes & 2 & 3 & I & 3 \\
\hline \multicolumn{5}{|l|}{ Infection } \\
\hline Oral candidiasis & 1 & 0 & I & 2 \\
\hline Vulvomycotic infection & 2 & I & I & $<1$ \\
\hline
\end{tabular}

Notes: Data from Doribax ${ }^{\circledast}$ (doripenem for injection) package insert, 2008. 
done with the purpose of evaluating the medical resources used by the surviving patients, and thus quantify the effect of mortality, if any, on the LOS, the LOS ICU, or the duration of the MV. The application of Kaplan-Meier curves showed only significant differences in the LOS $(p=0.011)$; this shows a limited effect of mortality on the different use of resources between the two treatment groups. Furthermore, an analysis was done only in patients with isolated strains of $P$. aeruginosa, with the purpose of evaluating the use of resources in the two treatment groups. According to the results, no significant differences were observed between the 30 patients receiving doripenem and the 26 patients receiving imipenem (median LOS 24 [95\% CI: 18-36] days vs 37 [95\% CI: 28-not available] days [p $=0.175]$; median LOS ICU 15 [95\% CI: 9-21] days vs 17 [95\% CI: 14-28] days $[\mathrm{p}=0.195]$; median duration of MV 7 [95\% CI: 5-9] days vs 13 [95\% CI: 7-29] days [p $=0.138]$ ).

Following the application of the Cox proportional hazards model, doripenem treatment (hazard ratio [HR]: 1.358; $\mathrm{p}=0.004)$ and ventilator-associated pneumonia in North America (HR: $1.617 ; \mathrm{p}<0.001$ ) were associated with a shorter LOS. Additionally, a tendency was observed of an association between early initiation of MV and a shorter LOS (HR: 1.227; $\mathrm{p}=0.058$ ). On the other hand, isolation of $P$. aeruginosa was associated with a longer LOS, but this did not reach statistical significance (HR: 0.759; $\mathrm{p}=0.121$ ). Similarly, treatment with doripenem (HR: 1.145 ; $\mathrm{p}=0.149)$ and having ventilator-associated pneumonia in North America (HR: 1.199; $\mathrm{p}=0.055$ ), were associated with a shorter LOS ICU; however, none of these variables reached statistical significance. On the other hand, baseline isolation of strains of $P$. aeruginosa (HR: 0.732; $p=0.035$ ) and the baseline APACHE II score (HR: 0.972; $p=0.003$ ) were associated with a longer LOS. Finally, treatment with doripenem (HR: 1.219; $\mathrm{p}=0.049$ ), baseline systolic blood pressure (HR: $1.005 ; \mathrm{p}=0.020$ ), and an APACHE II score $\leq 20$ (HR: $1.374 ; \mathrm{p}=0.011$ ) were associated with a shorter duration of MV, while the baseline isolation of strains of $P$. aeruginosa was associated with a longer duration of the MV (HR: 0.805; $\mathrm{p}=0.170$ ), but not with statistical significance.

\section{Dose and administration}

Doripenem is administered exclusively by parenteral route at a dose of $500 \mathrm{mg}$ every eight hours, in continuous infusion over one hour or over four hours in the case of nosocomial pneumonia, in patients over 18 years of age. ${ }^{1,52}$ Prolonging the infusion time has been reported as a more effective strategy than dose escalation to increase the PK/PD breakpoint. ${ }^{46}$ However, phase III clinical studies evaluating the administration of $1,000 \mathrm{mg}$ infused over four hours every eight hours for hospitalacquired pneumonia are undergoing clinical evaluation. ${ }^{48}$ Dosage in pediatric patients has not been studied yet. In patients with impaired renal function, the dose must be adjusted when creatinine $\mathrm{CL}$ is below $50 \mathrm{~mL} / \mathrm{min}$. When creatinine $\mathrm{CL}$ is $30-50 \mathrm{~mL} / \mathrm{min}$, administer $250 \mathrm{mg}$ every eight hours, and when creatinine $\mathrm{CL}<30 \mathrm{~mL} / \mathrm{min}, 250 \mathrm{mg}$ every 12 hours. Doripenem is eliminated by hemodialysis; however, at present there is insufficient information to recommend supplementary doses in patients undergoing hemodialysis. ${ }^{1}$

\section{Doripenem for the treatment of severe bacterial infections}

Doripenem's characteristics, which are similar to those of currently used carbapenem antibiotics, plus its slightly more potency against potentially multiresistant Gramnegative bacilli, could justify considering it as an alternative for multibacterial infections caused by multiresistant Gram-negative bacilli. The clinical trials conducted so far show an equivalence with respect to the most potent and effective first-choice antibiotics. Higher coverage rates against $P$. aeruginosa and $K$. pneumoniae isolates were observed in clinical trials, but without achieving statistical differences. Further studies may confirm the impact of treating infections caused by multidrug-resistant Gram-negative microorganisms. The advantages of an adequate empiric therapy are well known in the management of critical patients with severe infections such as ventilator-associated pneumonia and bacteremia, although the objectives of the studies conducted so far have not analyzed this issue.

The indications currently approved by EMEA are the treatment of complicated intra-abdominal infections, complicated urinary tract infections including pyelonephritis, and the treatment of nosocomial pneumonia, regardless of whether it is ventilator-associated or not. The studies show an equivalence with first-line drugs used so far; thus for these indications, it may be an alternative in empirical antimicrobial therapy.

\section{Disclosure}

The authors report no conflicts of interest in this work.

\section{References}

1. Doribax ${ }^{\circledR}$ (doripenem for injection) package insert. Titusville, NJ: Ortho-McNeil Pharmaceutical IR; 2008.

2. Davies TA, Shang W, Bush K, Flamm RK. Affinity of doripenem and comparators to penicillin-binding proteins in Escherichia coli and Pseudomonas aeruginosa. Antimicrob Agents Chemother. 2008;52(4):1510-1512. 
3. Keam SJ. Doripenem: a review of its use in the treatment of bacterial infections. Drugs. 2008;68(14):2021-2057.

4. Mori M, Hikida M, Nishihara T, Nasu T, Mitsuhashi S. Comparative stability of carbapenem and penem antibiotics to human recombinan dehydropeptidase-I. J Antimicrob Chemother. 1996;37(5):1034-1036.

5. Ge Y, Wikler MA, Sahm DF, Blosser-Middleton RS, Karlowsky JA. In vitro antimicrobial activity of doripenem, a new carbapenem. Antimicrob Agents Chemother. 2004;48(4):1384-1396.

6. Jones RN, Huynh HK, Biedenbach DJ, Fritsche TR, Sader HS. Doripenem (S-4661), a novel carbapenem: comparative activity against contemporary pathogens including bactericidal action and preliminary in vitro methods evaluations. J Antimicrob Chemother. 2004;54(1):144-154.

7. Jones RN, Huynh HK, Biedenbach DJ. Activities of doripenem (S-4661) against drug-resistant clinical pathogens. Antimicrob Agents Chemother. 2004;48(8):3136-3140.

8. Doribax ${ }^{\mathrm{TM}}$ (doripenem for injection) for Intravenous Infusion. 2007. Accessed on April 22, 2009. Available from: http:/www.fda.gov/cder/ foi/label/2007/022106lbl.pdf.

9. European Medicines Agency. Annex I: Summary of product characteristics. 2007. Accessed on April 22, 2009. Available from: http://www. emea.europa.eu/humandocs/PDFs/EPAR/doribax/H-891-PI-en.pdf.

10. Fritsche TR, Stilwell MG, Jones RN. Antimicrobial activity of doripenem (S-4661): a global surveillance report (2003). Clin Microbiol Infect. 2005;11(12):974-984.

11. Tsuji M, Ishii Y, Ohno A, Miyazaki S, Yamaguchi K. In vitro and in vivo antibacterial activities of S-4661, a new carbapenem. Antimicrob Agents Chemother. 1998;42(1):94-99.

12. Jones RN, Sader HS, Fritsche TR. Comparative activity of doripenem and three other carbapenems tested against Gram-negative bacilli with various beta-lactamase resistance mechanisms. Diagn Microbiol Infect Dis. 2005;52(1):71-74.

13. Traczewski MM, Brown SD. In vitro activity of doripenem against Pseudomonas aeruginosa and Burkholderia cepacia isolates from both cystic fibrosis and non-cystic fibrosis patients. Antimicrob Agents Chemother. 2006;50(2):819-821.

14. Chen Y, Garber E, Zhao Q, et al. In vitro activity of doripenem (S-4661) against multidrug-resistant gram-negative bacilli isolated from patients with cystic fibrosis. Antimicrob Agents Chemother. 2005;49(6): 2510-2511.

15. Mendes RE, Rhomberg PR, Bell JM, Turnidge JD, Sader HS. Doripenem activity tested against a global collection of Enterobacteriaceae, including isolates resistant to other extended-spectrum agents. Diagn Microbiol Infect Dis. 2009;63(4):415-425.

16. Castanheira M, Jones RN, Livermore DM. Antimicrobial activities of doripenem and other carbapenems against Pseudomonas aeruginosa, other nonfermentative bacilli, and Aeromonas spp. Diagn Microbiol Infect Dis. 2009;63(4):426-433.

17. Mushtaq S, Ge Y, Livermore DM. Comparative activities of doripenem versus isolates, mutants, and transconjugants of Enterobacteriaceae and Acinetobacter spp. with characterized beta-lactamases. Antimicrob Agents Chemother. 2004;48(4):1313-1319.

18. Livermore DM, Hope R, Brick G, Lillie M, Reynolds R. Non-susceptibility trends among Enterobacteriaceae from bacteraemias in the UK and Ireland, 2001-06. J Antimicrob Chemother. 2008; 62(Suppl 2):ii41-ii54.

19. Watanabe A, Takahashi $\mathrm{H}$, Kikuchi $\mathrm{T}$, et al. Comparative in vitro activity of S-4661, a new parenteral carbapenem, and other antimicrobial agents against respiratory pathogens. Chemotherapy. 2000;46(3):184-187.

20. Livermore DM, Hope R, Brick G, Lillie M, Reynolds R. Nonsusceptibility trends among Pseudomonas aeruginosa and other nonfermentative Gram-negative bacteria from bacteraemias in the UK and Ireland, 2001-06. J Antimicrob Chemother. 2008;62(Suppl 2): ii55-ii63.

21. Pillar CM, Torres MK, Brown NP, Shah D, Sahm DF. In vitro activity of doripenem, a carbapenem for the treatment of challenging infections caused by Gram-negative bacteria, against recent clinical isolates from the United States. Antimicrob Agents Chemother. 2008;52(12):4388-4399.
22. Marti S, Sanchez-Cespedes J, Alba V, Vila J. In vitro activity of doripenem against Acinetobacter baumannii clinical isolates. Int $J$ Antimicrob Agents. 2009;33(2):181-182.

23. Brown SD, Traczewski MM. Comparative in vitro antimicrobial activity of a new carbapenem, doripenem: tentative disc diffusion criteria and quality control. J Antimicrob Chemother. 2005;55(6):944-949.

24. Wexler HM, Engel AE, Glass D, Li C. In vitro activities of doripenem and comparator agents against 364 anaerobic clinical isolates. Antimicrob Agents Chemother. 2005;49(10):4413-4417.

25. Snydman DR, Jacobus NV, McDermott LA. In vitro activities of doripenem, a new broad-spectrum carbapenem, against recently collected clinical anaerobic isolates, with emphasis on the Bacteroides fragilis group. Antimicrob Agents Chemother. 2008;52(12):4492-4496.

26. Goldstein EJ, Citron DM, Merriam CV, Warren YA, Tyrrell KL, Fernandez HT. In vitro activities of doripenem and six comparator drugs against 423 aerobic and anaerobic bacterial isolates from infected diabetic foot wounds. Antimicrob Agents Chemother. 2008;52(2):761-766.

27. Hecht DW, Galang MA, Sambol SP, Osmolski JR, Johnson S, Gerding DN. In vitro activities of 15 antimicrobial agents against 110 toxigenic Clostridium difficile clinical isolates collected from 1983 to 2004. Antimicrob Agents Chemother. 2007;51(8):2716-2719.

28. Mikamo H, Izumi K, Hua YX, Hayasaki Y, Sato Y, Tamaya T. In vitro and in vivo antibacterial activities of a new injectable carbapenem, S-4661, against gynaecological pathogens. J Antimicrob Chemother. 2000;46(3):471-474.

29. Zhanel GG, Wiebe R, Dilay L, et al. Comparative review of the carbapenems. Drugs. 2007;67(7):1027-1052.

30. Mushtaq S, Ge Y, Livermore DM. Doripenem versus Pseudomonas aeruginosa in vitro: activity against characterized isolates, mutants, and transconjugants and resistance selection potential. Antimicrob Agents Chemother. 2004;48(8):3086-3092.

31. Masuda N, Sakagawa E, Ohya S, Gotoh N, Tsujimoto H, Nishino T. Substrate specificities of MexAB-OprM, MexCD-OprJ, and MexXYOprM efflux pumps in Pseudomonas aeruginosa. Antimicrob Agents Chemother. 2000;44(12):3322-3327.

32. Pumbwe L, Glass D, Wexler HM. Efflux pump overexpression in multiple-antibiotic-resistant mutants of Bacteroides fragilis. Antimicrob Agents Chemother. 2006;50(9):3150-3153.

33. Ishii Y, Galleni M, Ma L, Frere JM, Yamaguchi K. Biochemical characterisation of the CTX-M-14 beta-lactamase. Int J Antimicrob Agents. 2007;29(2):159-164.

34. Davies TA, Shang W, Bush K, Flamm RK. Activity of doripenem and comparator beta-lactams against US clinical isolates of Streptococcus pneumoniae with defined mutations in the penicillin-binding domains of pbp1a, pbp2b and pbp2x. J Antimicrob Chemother. 2008;61(3):751-753.

35. Huynh HK, Biedenbach DJ, Jones RN. Delayed resistance selection for doripenem when passaging Pseudomonas aeruginosa isolates with doripenem plus an aminoglycoside. Diagn Microbiol Infect Dis. 2006;55(3):241-243.

36. Credito KL, Ednie LM, Appelbaum PC. Comparative antianaerobic activities of doripenem determined by MIC and time-kill analysis. Antimicrob Agents Chemother. 2008;52(1):365-373.

37. Tsuji M, Matsuda H, Miwa H, Miyazaki S. Antimicrobial-induced release of endotoxin from Pseudomonas aeruginosa: comparison of in vitro and animal models. J Antimicrob Chemother. 2003;51(2):353-359.

38. Drusano GL, Preston SL, Hardalo C, et al. Use of preclinical data for selection of a phase II/III dose for evernimicin and identification of a preclinical MIC breakpoint. Antimicrob Agents Chemother. 2001;45(1):13-22.

39. Bhavnani SM, Hammel JP, Cirincione BB, Wikler MA, Ambrose PG. Use of pharmacokinetic-pharmacodynamic target attainment analyses to support phase 2 and 3 dosing strategies for doripenem. Antimicrob Agents Chemother. 2005;49(9):3944-3947.

40. Andes DR, Craig WA. In vivo pharmacodynamic activity of a new carbapenem, doripenem (DOR), against multiple bacteria in a murine thigh infection model. Chicago, IL: 43rd Interscience Conference on Antimicrobial Agents and Chemotherapy; 2003, Sep 13-17. 
41. Kim A, Banevicius MA, Nicolau DP. In vivo pharmacodynamic profiling of doripenem against Pseudomonas aeruginosa by simulating human exposures. Antimicrob Agents Chemother. 2008;52(7):2497-2502.

42. Katsube T, Yano Y, Yamano Y, Munekage T, Kuroda N, Takano M. Pharmacokinetic-pharmacodynamic modeling and simulation for bactericidal effect in an in vitro dynamic model. J Pharm Sci. 2008;97(9):4108-4117.

43. Yano Y, Oguma T, Nagata H, Sasaki S. Application of logistic growth model to pharmacodynamic analysis of in vitro bactericidal kinetics. J Pharm Sci. 1998;87(10):1177-1183.

44. Katsube T, Yamano Y, Yano Y. Pharmacokinetic-pharmacodynamic modeling and simulation for in vivo bactericidal effect in murine infection model. J Pharm Sci. 2008;97(4):1606-1614.

45. Nagasawa Z, Kusaba K, Aoki Y. Susceptibility of clinical isolates of Pseudomonas aeruginosa in the Northern Kyushu district of Japan to carbapenem antibiotics, determined by an integrated concentration method: evaluation of the method based on Monte Carlo simulation. $J$ Infect Chemother. 2008;14(3):238-243.

46. Ikawa K, Morikawa N, Uehara S, et al. Pharmacokinetic-pharmacodynamic target attainment analysis of doripenem in infected patients. Int $J$ Antimicrob Agents. 2009;33(3):276-279.

47. Wagenlehner FM, Wagenlehner C, Redman R, Weidner W, Naber KG. Urinary bactericidal activity of doripenem versus that of levofloxacin in patients with complicated urinary tract infections or pyelonephritis. Antimicrob Agents Chemother. 2009;53(4):1567-1573.

48. Van Wart SA, Andes DR, Ambrose PG, Bhavnani SM. Pharmacokineticpharmacodynamic modeling to support doripenem dose regimen optimization for critically ill patients. Diagn Microbiol Infect Dis. 2009;63(4):409-414.

49. Ikawa K, Morikawa N, Urakawa N, Ikeda K, Ohge H, Sueda T. Peritoneal penetration of doripenem after intravenous administration in abdominalsurgery patients. J Antimicrob Chemother. 2007;60(6):1395-1397.

50. Hori T, Nakano M, Kimura Y, Murakami K. Pharmacokinetics and tissue penetration of a new carbapenem, doripenem, intravenously administered to laboratory animals. In Vivo. 2006;20(1):91-96.

51. Cirillo I, Mannens G, Janssen C, et al. Disposition, metabolism, and excretion of [14C]doripenem after a single 500-milligram intravenous infusion in healthy men. Antimicrob Agents Chemother. 2008;52(10):3478-3483.

52. Cirillo I, Redman R, Vaccaro N, et al. Pharmacokinetics of doripenem in subjects with varying degrees of renal impairment. Washington, DC: 48th Annual Interscience Conference on Antimicrobial Agents and Chemotherapy and 46th Annual Meeting of the Infectious Diseases Society of America; 2008, Oct 25-28.

53. Nakajima Y, Mizobuchi M, Nakamura M, et al. Mechanism of the drug interaction between valproic acid and carbapenem antibiotics in monkeys and rats. Drug Metab Dispos. 2004;32(12):1383-1391.

54. Horiuchi M, Kimura M, Tokumura M, Hasebe N, Arai T, Abe K. Absence of convulsive liability of doripenem, a new carbapenem antibiotic, in comparison with beta-lactam antibiotics. Toxicology. 2006; 222(1-2):114-124.

55. Kobayashi Y. Study of the synergism between carbapenems and vancomycin or teicoplanin against MRSA, focusing on S-4661, a carbapenem newly developed in Japan. J Infect Chemother. 2005;11(5):259-261.
56. Psathas PA, Kuzmission A, Ikeda K, Yasuo S. Stability of doripenem in vitro in representative infusion solutions and infusion bags. Clin Ther. 2008;30(11):2075-2087.

57. Brammer MK, Chan P, Heatherly K, et al. Compatibility of doripenem with other drugs during simulated Y-site administration. Am J Health Syst Pharm. 2008;65(13):1261-1265.

58. Réa-Neto A, Niederman M, Lobo SM, et al. Efficacy and safety of doripenem versus piperacillin/tazobactam in nosocomial pneumonia: a randomized, open-label, multicenter study. Curr Med Res Opin. 2008;24(7):2113-2126

59. Chastre J, Wunderink R, Prokocimer P, Lee M, Kaniga K, Friedland I. Efficacy and safety of intravenous infusion of doripenem versus imipenem in ventilator-associated pneumonia: a multicenter, randomized study. Crit Care Med. 2008;36(4):1089-1096.

60. Gilbert D. 'The truth, if it exists, is in the details'. Crit Care Med. 2008; 36(4):1368-1369.

61. Lucasti C, Jasovich A, Umeh O, Jiang J, Kaniga K, Friedland I. Efficacy and tolerability of IV doripenem versus meropenem in adults with complicated intra-abdominal infection: a phase III, prospective, multicenter, randomized, double-blind, noninferiority study. Clin Ther. 2008;30(5):868-883.

62. Owens RC, Jr. An overview of harms associated with beta-lactam antimicrobials: where do the carbapenems fit in? Crit Care. 2008; 12(Suppl 4):S3.

63. Thye DA, Kilfoil T, Leighton A, Wikler M. Doripenem: a phase 1 study to evaluate safety, tolerability and pharmacokinetics in a Western healthy volunteer population. Chicago, IL: 43rd Interscience Conference on Antimicrobial Agents and Chemotherapy; 2003, Sep 14-17.

64. Saito A, Inamatsu T, Shimada J. Clinical studies of S-4661, new parenteral carbapenem antibiotic, in chronic respiratory tract infections. Toronto, Canada: 37th Interscience Conference on Antimicrobial Agents and Chemotherapy; 1997, Sep-Oct 28-1.

65. Floren L, Wikler M, Kilfoil T, Ge Y. A phase I, double-blind, placebo-controlled study to determine the safety, tolerability, and pharmacokinetics (PK) of prolonged-infusion regimens of doripenem (DOR) in healthy subjects. Washington, DC: 44th Interscience Conference on Antimicrobial Agents and Chemotherapy; 2004, Oct-Nov 30-2.

66. Sodhi M, Axtell SS, Callahan J, Shekar R. Is it safe to use carbapenems in patients with a history of allergy to penicillin? J Antimicrob Chemother. 2004;54(6):1155-1157.

67. Prescott WA Jr, DePestel DD, Ellis JJ, Regal RE. Incidence of carbapenem-associated allergic-type reactions among patients with versus patients without a reported penicillin allergy. Clin Infect Dis. 2004;38(8):1102-1107.

68. McConnell SA, Penzak SR, Warmack TS, Anaissie EJ, Gubbins PO. Incidence of imipenem hypersensitivity reactions in febrile neutropenic bone marrow transplant patients with a history of penicillin allergy. Clin Infect Dis. 2000;31(6):1512-1514.

69. Merchant S, Gast C, Nathwani D, et al. Hospital resource utilization with doripenem versus imipenem in the treatment of ventilator-associated pneumonia. Clin Ther. 2008;30(4):717-733.
Drug Design, Development and Therapy

\section{Publish your work in this journal}

Drug Design, Development and Therapy is an international, peerreviewed open-access journal that spans the spectrum of drug design and development through to clinical applications. Clinical outcomes, patient safety, and programs for the development and effective, safe, and sustained use of medicines are a feature of the journal,

\section{Dovepress}

which has also been accepted for indexing on PubMed Central. The manuscript management system is completely online and includes a very quick and fair peer-review system, which is all easy to use. Visit http://www.dovepress.com/testimonials.php to read real quotes from published authors. 